\title{
LO SVILUPPO DEL CONTROLLO ACCENTRATO DI COSTITUZIONALITÀ IN AMERICA LATINA E IL SUO RUOLO NELLE MODERNE DEMOCRAZIE: VERSO LA COSTRUZIONE DI UNO JUS COMMUNE DEL DIRITTO PROCESSUALE COSTITUZIONALE?
}

\author{
El desarrollo del control centralizado de \\ constitucionalidad en América Latina y su papel en \\ las democracias modernas: ¿̇hacia la construcción de \\ un jus commune de derecho procesal constitucional? \\ GIANCARLO ROLLA \\ Università degli Studi di Genova \\ rolla@unige.it
}

Cómo citar/Citation

Rolla, G. (2021).

Lo sviluppo del controllo accentrato di costituzionalità in America latina e il suo ruolo nelle moderne democrazie: verso la costruzione di uno jus commune del diritto processuale costituzionale? Anuario Iberoamericano de Justicia Constitucional, 25(2), 285-340. doi: https://doi.org/10.18042/cepc/aijc.25.09

Resumen

Cien años después de la entrada en vigor de la Constitución austríaca en 1920, esta obra tiene por objeto, en primer lugar, poner de relieve tanto la novedad que representa la justicia constitucional, en comparación con las formas anteriores de control de la constitucionalidad, como las transformaciones que ha experimentado el «modelo» austríaco durante su circulación en Europa y en América Latina. Posteriormente, se examina con mayor profundidad el papel diferente que desempeñan los tribunales constitucionales tanto en las fases posteriores a una ruptura constitucional o durante una transición democrática como en los períodos de democracia «madura». En ambos contextos se intenta poner de relieve las técnicas interpretativas utilizadas por los tribunales constitucionales para armonizar los 
valores constitucionales con la sociedad y dialogar con los demás poderes del Estado. Por último, se subraya la creciente participación de los jueces constitucionales en la resolución de cuestiones de importancia política e institucional.

\section{Palabras clave} judicial.

Justicia constitucional; derecho constitucional comparado; la interpretación

\section{Abstract}

One hundred years after the entry into force of the Austrian Constitution in 1920 , this work aims, first of all, to highlight both the novelty of constitutional justice in comparison with previous forms of control of constitutionality, and the transformations that the Austrian «model» has undergone during its circulation in Europe and in Latin America. Subsequently, the different role played by the Constitutional Courts both in the phases following a constitutional rupture or during a democratic transition, and in periods of «mature» democracy is examined in greater depth. In both contexts, an attempt is made to highlight the interpretative techniques used by the Constitutional Courts to harmonize constitutional values with society and to engage in dialogue with Parliament and Judges. Finally, the growing involvement of constitutional Court in resolving issues of political and institutional importance is highlighted.

\section{Keywords}

Constitutional Justice; Comparative constitutional law; Judicial interpretation. 


\section{SOMMARIO}

I. ALCUNE CONSIDERAZIONI PRELIMINARI DI NATURA METODOLOGICA. II. LA NASCITA IN AUSTRIA DI UNA ALTERNATIVA ALLE FORME OTTOCENTESCHE DI GARANZIA COSTITUZIONALE. III. LA COMPLESSA DIFFUSIONE DEL MODELLO «AUSTRIACO» IN AMERICA LATINA. IV. IL RUOLO DEI TRIBUNALI COSTITUZIONALI NELLE TRANSIZIONI DEMOCRATICHE IL RAPPORTO CON IL PASSATO. V. L'APPORTO DEI TRIBUNALI COSTITUZIONALI PER CONFERIRE EFFETTIVITÀ ALLE NORME COSTITUZIONALI AMPLIANDO L'OGGETTO E IL PARAMETRO DEL SINDACATO DI COSTITUZIONALITÀ. VI. IL RUOLO DEI TRIBUNALI COSTITUZIONALI NELLE FASI DI DEMOCRAZIA «MATURA». LA MOLTEPLICITÀ DELLE TECNICHE IDONEE A CONSENTIRE AI TRIBUNALI COSTITUZIONALI DI DIALOGARE CON GLI ATTORI DEL SISTEMA COSTITUZIONALE. VII. I TIPI DI SENTENZE FINALIZZATE A REGOLARE I RAPPORTI TRA I TRIBUNALI COSTITUZIONALI, IL PARLAMENTO E I GIUDICI. VIII. L'ACCENTUAZIONE DI NUOVE FORME DI «POLITICITÀ» DELLA GIURISPRUDENZA COSTITUZIONALE. VERSO UNA RIDEFINIZIONE DELLA NOZIONE DI POLITICAL QUESTION. BIBLIOGRAFIA.

\section{ALCUNE CONSIDERAZIONI PRELIMINARI DI NATURA METODOLOGICA}

Cento anni fa, la Costituzione federale della Repubblica d'Austria, istituendo un' Alta Corte costituzionale, ha previsto all'art. 140 un nuovo organo la cui esperienza darà vita a un nuovo tipo di sindacato di costituzionalità, contrapposto alle preesistenti forme di judicial review e di controllo «politico» della Costituzione. Queste pagine si propongono di approfondire la specificità delle forme di giustizia costituzionale originate dal prototipo "austriaco" e la sua diffusione in America latina; nonché di individuare alcune problematiche che i Tribunali costituzionali hanno dovuto affrontare in questi ultimi anni.

A tal fine è necessario sviluppare una comparazione che avvenga sia sul piano diacronico, che su quello degli ambiti geografici coinvolti dalla circolazione giuridica dell'istituto: si tratta di un obiettivo che, a nostro avviso, possiede una validità metodologica in quanto i sistemi giuridici dei continenti europeo e americano, nonostante le evidenti peculiarità, appartengono alla medesima "famiglia giuridica", 
in quanto la loro evoluzione ha fatto riferimento ai principi del costituzionalismo elaborati dalle rivoluzioni liberali del secolo XIX'1.

Tuttavia, non va trascurato che queste esperienze, pur possedendo un'unitarietà' di fondo, si sono sviluppate lungo percorsi distinti, dando vita a tradizioni costituzionali diverse: è indubbio che il continente americano abbia affrontato, nel tempo, il tema dei modi di tutela e garanzia della Costituzione secondo un percorso originale, che ha indotto un'autorevole dottrina a sostenere che l' "Europa es la matriz, pero Amèrica latina es una realidad propia"2. Sinteticamente si possono individuare tra fasi distinte, nel senso che il costituzionalismo latinoamericano si è ispirato, prima, alle teorie della difesa "politica" della Costituzione, quindi, ha fatto riferimento alla judicial review nordamericana, mentre in tempi più recenti appare influenzato dai sistemi europei di giustizia costituzionale, caratterizzati da un controllo concentrato, esercitato da un organo ad hoc capace di sanzionare con effetti erga omnes le norme contrarie alla Costituzione ${ }^{3}$.

Nel corso del secolo XIX fu preminente l'attrazione esercitata dal pensiero giuridico francese e dalla sua variante spagnola.

In Francia, non si negava che la legge potesse essere ingiusta o lesiva dei diritti individuali, ma si escludeva che tale vulnus potesse essere sanato dall'ordine giudiziario, la cui funzione doveva consistere nel dare attuazione alla volontà del legislatore: i giudici dovevano essere la "bocca" attraverso cui parla la legge. Di conseguenza, il compito di assicurare il rispetto della Costituzione doveva essere attribuito - in ossequio al principio della sovranità nazionalea un organo politicamente rappresentativo, se non direttamente al corpo elettorale cui era stato inizialmente riconosciuta la competenza di esercitare una censura sulle leggi ${ }^{4}$. Mentre altre proposte attribuirono — di volta in voltatale compito a specifici organi, come il Senato, il "tribunale di censori" o una jurie constitutionnaires.

In Spagna, la Costituzione di Bayona del 1808 riservava al Senato la competenza di "velar sobre la conservación de la libertad individual y de la libertad de

1 Sulle basi storiche e teoriche del costituzionalismo: Blanco Valdés, 1994; Jiménez Asensio, 2001; Floridia, 1991; Fioravanti, 2009. Con riferimento all'America latina: Soberanes Fernández, 1992.

2 Così: García Balaunde, 2003, 66; Gross Espiell, 2002, 149.

3 Sulle influenze culturali del costituzionalismo in América Latina: Andrews, 2011: 5; Eissa Barroso, 2010: 97; M. Ferrer Muñoz et alt, 1996; Brewer Carías, 2014.

4 Ad esempio, l'art. 27 della Costituzione francese del 1793 (mai entrata in vigore) riconosceva il diritto di censura contro tutte le leggi e qualsiasi atto del legislatore contrario alla Costituzione.

5 Tale organo, individuato da Sieyès, avrebbe dovuto essere costituito da 108 membri di derivazione parlamentare che, annualmente, si rinnovavano per un terzo attraverso cooptazione. Tra le sue competenze vi era quella di presentare periodicamente delle proposte di riforma della Costituzione e, soprattutto, di assicurare la tutela dei diritti lesi dal legislatore. In dottrina: Battaglini, 1957. 
la imprenta"6; mentre la Costituzione di Cadice del 1812 imponeva al Parlamento di prendere in esame "le particolari infrazioni della Costituzione delle quali fossero stati informati, onde porvi l'opportuno rimedio e rendere effettiva la responsabilità de'contravventori". A sua volta, l'articolo successivo riconosceva a ogni spagnolo il diritto di reclamare, innanzi alle Corti o presso al Re, l'osservanza della Costituzione ${ }^{7}$. Identica formulazione si rinviene nella Costituzione del Regno delle due Sicilie del $1820^{8}$.

Mentre l'art. 70 del progetto di Costituzione federale della Prima Repubblica spagnola del 1873 individuò nuovamente nel Senato l'organo che avrebbe dovuto sospendere, per un periodo di tre anni, la promulgazione delle leggi ritenute lesive dei diritti fondamentali ${ }^{9}$.

In Germania, il titolo V della Costituzione dell'Impero del 1849 riservava a un organo apposito - il Tribunale dell'Impero- la giurisdizione sulle controversie costituzionali, sui ricorsi dei cittadini contro violazioni dei diritti riconosciuti dalla Costituzione imperiale o contro violazioni della Costituzione di un Land $^{10}$. Mentre nel caso del Belgio i cittadini potevano esercitare un generico diritto di petizione alle autorità pubbliche a tutela dei diritti costituzionali ${ }^{11}$.

In América Latina, infine, l'influenza delle Carte costituzionali spagnole condizionò in misura predominante il periodo successivo alla crisi coloniale: infatti, le Costituzioni del periodo dell'Indipendenza, pur richiamandosi ai canoni del costituzionalismo liberale, evidenziano un'ampia circolazione di soluzioni costituzionali in cui elementi propri della cultura americana si fondano con istituti della tradizione spagnola ${ }^{12}$.

Emblematica è l'esperienza degli Stati Uniti del Messico, che si segnala per la varietà dei riferimenti e delle soluzioni adottate nel tempo. Se nel Decreto costituzionale para la libertà de la America Medicina del 22 ottobre 1814 il difensore della Costituzione fu individuato nella figura del Supremo Odierno cui competeva proteggere i diritti di libertà, proprietà, eguaglianza e sicurezza ${ }^{13}$, la Costituzione federale del 1824 attribuì, invece, a ciascuna delle due Camere la competenza di decidere, in qualità di gran guardo, sulla responsabilità dei governatori statali per violazione della Costituzione o per l'approvazione di leggi incostituzionali ${ }^{14}$.

Art. 39.

Artt. 372 e 373.

Artt. 359 e 360 facenti parte del Titolo X dedicato a "Osservanza della Costituzione e del modo di procedere per farvi de' cangiamenti”.

9 Sánchez Agesta, 1984; Ruiz Lapeña, 1982; Iacometti, 2009: 373.

10 Art. 126 della Costituzione dell'Impero tedesco del 1849. In dottrina: Luther, 1990; Palici di Suni, 2013.

11 Art. 21 della Costituzione del Belgio del 1831.

12 Garriga, 2010; Annino y Ternavasio, 2012; Ferrer Muñoz y Luna Carrasco, 1996; García Laguardia, 1971; Fernández Segado, 1997: 82.

13 Art. 165

14 Art. 38. 
Successivamente, la Legge costituzionale del 1836 istituì un "Supremo Poder Conservador" che, ispirandosi al Senato francese, aveva il compito, tra l'altro, di dichiarare la nullità di una legge o di un decreto per violazione di un articolo specifico della Costituzione nei due mesi successivi alla sua adozione ${ }^{15}$. Solo nel 1857 la Costituzione politica introdusse un radicale cambio di prospettiva, aprendo il sistema delle garanzie costituzionali all'influenza della judicial review: infatti, l'art. 101 attribuiva ai tribunali federali la competenza sulle controversie nei confronti di leggi o di atti dei pubblici poteri lesivi dei diritti individuali.

Altri ordinamenti dell'America latina si sono inizialmente ispirati al "fascino discreto" della tradizione spagnola: la competenza a garantire il rispetto delle disposizioni costituzionale fu attribuita, di volta in volta, a organi consultivi come il Consiglio di Stato (la Costituzione ecuadoriana del 1851), a organi interni al potere legislativo (la Costituzione politica della Bolivia del 1826, della Costa Rica del 1821, del Brasile del 1824, del Perù del 1823). Mentre la Costituzione boliviana del 1826, su influenza del pensiero di Simón Bolívar, istituì una "Camera dei censori" con il duplice compito di controllare il rispetto della Costituzione, delle leggi, dei Trattati internazionali, nonché di esercitare l'accusa innanzi al Senato in caso di violazioni del diritto ${ }^{16}$.

Facendo riferimento alle esperienze di giustizia costituzionale ancora attive in America latina, è necessario premettere che esse hanno registrato nel tempo una duplice mutazione. Prima, nella seconda metà del secolo XIX, alcuni ordinamenti superarono le iniziali procedure di controllo politico della conformità alla Costituzione degli atti pubblici, optando per sistemi di judicial review di ispirazione nordamericana: come nel caso, ad esempio, del Messico, dell'Argentina, del Brasile, del Venezuela e di Cuba.

In Messico, con l'approvazione della Costituzione del 1857 i Tribunali della Federazione e la Corte Suprema in via di appello hanno acquisito la competenza a decidere su ogni controversia che nasca da un contenzioso inerente ad atti legislativi o di qualsiasi altra autorità pubblica che violino la garanzie individuali (art. 101), oppure che sorga da un conflitto di competenza tra gli Stati o tra questi e la Federazione (art. 98) ${ }^{17}$. Mentre in Argentina l'art. 100 della Costituzione del 1857 attribuì alla Corte Suprema e ai tribunali inferiori "le conoscimento y decisioni de todas las causas que versen sobre puntos regidos por la Constitución”.

Con riferimento al Brasile, si può richiamare l'art. 59 della Costituzione del 1891 che riservò al Tribunale federale la competenza a decidere su ricorsi che contestavano la compatibilità con la Costituzione federale delle leggi e degli atti dei Governi statali. A Cuba, la prima Costituzione repubblicana del 1901 ha codificato il principio che la difesa delle norme costituzionali compete al potere

15 Art. 12.

16 Art. 50. In merito al pensiero costituzionale di Simón Bolívar si veda: Rozo Acuña, 2007; Scocozza, 2003: 297.

17 Castro Lozano, 2002. 
giudiziario sulla base di una controversia tra le parti che può essere sollevata (come ricorso di appello) innanzi al Tribunale Supremo, che decide con sentenza aventi effetti erga omnes ${ }^{18}$. Mentre una disciplina simile era stata già introdotta dal Codice di procedura civile venezuelano del 1897, il cui art. 334 stabiliva che "en caso de incompatibilidad entre esta Constitución y una ley u otra norma jurídica, se aplicarán las disposiciones constitucionales, correspondiendo a los tribunales en cualquier causa, aun de oficio, decidir lo conducente"19.

Una seconda modificazione nel modo di garantire la regolarità costituzionale all'interno di un ordinamento si ebbe nella seconda metà del secolo $\mathrm{XX}$, allorché iniziarono a diffondersi anche sistemi accentrati di giustizia costituzionale che, sulla scia della brevissima esperienza del Tribunale di garanzie costituzionali e sociali di Cuba, sperimentarono forme astratte di controllo di costituzionalità. Attualmente, quindi, continente latinoamericano si caratterizza per un articolato patchwork di soluzioni costituzionali in materia di controllo di costituzionalità, che rappresentano per il comparatista un vero laboratorio di formule costituzionali ${ }^{20}$.

\section{LA NASCITA IN AUSTRIA DI UNA ALTERNATIVA ALLE FORME OTTOCENTESCHE DI GARANZIA COSTITUZIONALE}

Nel corso del secolo XX il controllo politico della Costituzione divenne recessivo e fu utilizzato, comunque, non in alternativa, ma come strumento complementare alla giustizia costituzionale ${ }^{21}$. La precedente alternativa tra judicial review e difesa politica della Costituzione perde di vitalità in conseguenza della nascita e del diffondersi in Europa continentale di una nuova forma di giustizia costituzionale: la Verfassunsgerichtsbarkeit che codificata nella Costituzione austriaca del 1920 e prende forma grazie a un fecondo rapporto tra scelte normative e dottrina giuspubblicistica di lingua tedesca ${ }^{22}$.

\section{Art. 83.}

19 Si veda per riferimenti generali: Fernández Segado, 2000.

Va, tuttavia, segnalato, che sull'originario ceppo di influenza nordamericana si sono innestate altre competenze proprie della tradizione latinoamericana: tra tutti i ricorsi diretti a tutela dei diritti costituzionali, i ricorsi di gruppo a tutela degli interessi diffusi, le azioni popolari e i ricorsi contro le omissioni del legislatore. Per riferimenti dottrinali su tali esperienze, mi sia consentito rinviare a:. Rolla, 2012.

20 Sulle caratteristiche generali della giustizia costituzionale in America latina: Fernández Segado, 2000; Nogueira Alcala, 2003: 59; Fiz Zamudio, 1991; Ferrer Mac-Gregor, 2002.

21 E' il caso, ad esempio, degli ordinamenti in cui organi interni al Parlamento esprimono un parere vincolante sulla conformità alla Costituzione delle proposte di legge ovvero si riconosce al Capo dello Stato la facoltà di non promulgare una legge in caso di dubbia costituzionalità.

22 Vedi, per tutti, Cruz Villalón, 1987. 
In Austria, ancora nel 1867 la legge fondamentale sul Potere giudiziario precisava all'art. 7 che i giudici non hanno competenza a giudicare sulla validità delle leggi regolarmente promulgate, ma solo sulla validità dei regolamenti nel corso dei processi; inoltre, ribadiva il criterio che i conflitti normativi dovessero essere risolti in via preventiva, anteriormente alla loro pubblicazione. In questo contesto legislativo si è inserita la proposta di Georg Jellinek il quale, nel volume Una Corte costituzionale per l'Austria pubblicato nel 1885, ipotizzò l'istituzione di un giudice costituzionale competente a esercitare le funzioni di natura sostanzialmente giurisdizionale esercitate in precedenza dalle autorità amministrative (a proposito dei conflitti di competenza) e dalle Camere (in tema di conflitti tra legislazione ordinaria e costituzionale, tra Reich e Länder, di giudizi sulla regolarità delle elezioni).

L' Autore escluse la possibilità di attribuire ai giudici un sindacato diffuso, in quanto ritenuto poco coerente con il principio della certezza del diritto, preferendo affidare le competenze di cui sopra a un Tribunale già esistente: tale organo fu individuato nel Tribunale dell'Impero che, istituito nel 1867, esercitava alcune competenze di rilevanza costituzionale come i conflitti di competenza e i ricorsi dei cittadini a tutela dei diritti politici.

Un'ulteriore tappa nel lento processo di messa a fuoco del controllo accentrato di costituzionalità si ebbe nel 1919 allorché, in sede di dibattito costituente, fu proposto che il Tribunale costituzionale assorbisse le competenze del Tribunale dell'Impero; mentre, pochi mesi dopo, nel febbraio 1920, Kelsen caldeggiò sia il superamento del principio secondo cui i controlli debbano essere preventivi alla pubblicazione degli atti normativi, sia l'attribuzione alla Corte costituzionale della competenza a giudicare le leggi statali che, all'atto della loro applicazione, appaiono in contrasto con le disposizioni della Costituzione. Ad avviso di tale Autore inoltre, le sentenze dovevano produrre effetti non retroattivi, ma exnunc.

Successivamente, una proposta presentata dal Land del Tirolo si prefisse di superare il disallineamento esistente tra il controllo delle leggi federali e di quelle dei Länder, riconoscendo una "parità delle armi" tra i livelli istituzionali, ammettendo la possibilità di un controllo successivo sulle leggi federali da presentare entro 14 giorni dalla loro promulgazione. Da ultimo, in sede di discussione del progetto di Costituzione, il controllo di costituzionalità divenne un istituto generale finalizzato ad affermare la primazia delle norme costituzionali sulle altre fonti: la legge poteva essere impugnata per dubbio di costituzionalità sia ante che post la sua pubblicazione e la Corte divenne, a pieno titolo, un guardiano oggettivo della Costituzione.

Il modello "austriaco" si perfeziona, infine, con altre due integrazioni che, da un lato, consentono alla Corte di fissare la data a partire dalla quale le norme incostituzionali non sono più applicabili; dall'altro lato, riconoscono il potere dei 
giudici di disapplicare le norme dichiarate incostituzionali ai sensi dell'art. 140 della Legge costituzionale austriaca del $1920^{23}$.

Due importanti esperienze, introdotte in ambiti culturali differenti, hanno costituito un ponte tra il giudice costituzionale del 1920 e i Tribunali che si affermarono nella seconda metà del XX secolo, prima nel vecchio continente e, poi, in America latina: si tratta del Tribunal de garantías constitucionales della Seconda Republica spagnola del 1931 e del Tribunal de garantías constitucionales y sociales previsto dalla Constituzione di Cuba del 1940.

Il primo organo ha rappresentato la prima effettiva esperienza di giurisdizione costituzionale in Spagna: è interessante evidenziare come nell 'iter istitutivo si sia passati da un'ipotesi di controllo politico alla scelta di un sistema che si ispirava alla Costituzione austriaca del $1820^{24}$. Infatti, nel progetto costituzionale elaborato dall'apposita Commissione parlamentare si pensò di affidare al Tribunale delle Garanzie costituzionali un ruolo soltanto istruttorio, in quanto nel corso dell' iter legis avrebbe potuto presentare una relazione motivata al Presidente della Repubblica affichè chieda al Parlamento di procedere alla sua revisione. Il Presidente, una volta riapprovata la legge, avrebbe potuto promulgarla oppure sottoporla a un referendum popolare.

Successivamente, la stesura finale della Costituzione del 1931 e la successiva la legge organica del 1933 non solo riconobbero la competenza dei giudici a presentare un ricorso di incostituzionalità delle leggi ${ }^{25}$, ma anche affidarono al Tribunal de garantías constitucionales importanti competenze come i ricorsi di amparo a tutela dei diritti, la risoluzione dei conflitti tra Stato e Regioni, i ricorsi di incostituzionalità promossi da "toda persona individual o colectiva aunque non hubiera sido directamente agraviada" ${ }^{\text {"6 }}$, i giudizi di responsabilità penale del Presidente della Repubblica, del Fiscal della Repubblica e dei componenti il Tribunale Supremo.

I costituenti repubblicani non disconobbero l'importanza di introdurre un meccanismo a difesa dei nuovi principi affermati dalla Repubblica spagnola, ma nel medesimo tempo manifestarono - tanto in fase di elaborazione del testo costituzionale quanto nell' iter di approvazione della Costituzione- il timore che un'opzione netta a favore della judicial review potesse "mettere nella mani dei giudici" il potere di frenare lo sviluppo di una legislazione sociale che il governo repubblicano intendeva perseguire. La soluzione più idonea fu, quindi, rinvenuta nella coetanea esperienza del Tribunale costituzionale austriaco, facilitata sul

23 A proposito del c. d. "modello" austriaco: Cruz Villalón, 1987; Caravita, 1985; Roherssen, 1983.

24 Bassols Coma, 1981; Cascajo Castro, 1978: 243; Rubio Llorente, 1982-1983: 27; Cruz Villalón, 1982: 114; Ruiz Lapeña, 1982; Cascajo de Castro, 1978: 243.

25 Art. 100 Costituzione del 1931.

26 Art. 123 Costituzione del 1931. 
piano culturale dalla buona conoscenza della dottrina di lingua tedesca da parte di diversi, influenti componenti le Cortes constituyentes ${ }^{27}$.

Nel contesto americano, invece, va segnalata la breve esperienza a Cuba del Tribunal de garantías constitucionales y Sociales che, per quanto poco studiata nel continente europeo, appare di interesse per il comparatista, in quanto costituisce un esempio di ibrido tra judicial review e controllo astratto di costituzionalità.

La peculiare storia politica e giuridica dell'isola caraibica ha favorito la nascita di un esperimento che ha esercitato una significativa attrazione all'interno del costituzionalismo dell'America latina, realizzando un "ponte" tra i sistemi concreti (tramite la competenza a decidere sui ricorsi di amparo e a esercitare un giudizio di appello avverso le decisioni di habeas corpus) e quelli astratti (in virtù del controllo di costituzionalità delle norme e dei provvedimenti dei pubblici poteri, che poteva essere attivato sia con ricorso diretto, sia in virtù di una questione di legittimità prospettata da un giudice) ${ }^{28}$.

Come affermato da García Balunde l'esperienza cubana del 1949 si presenta come il tentativo di dar vita in America latina un tipo di giustizia costituzionale concentrata, attraverso la creazione all'interno del Tribunal Supremo di una Sala costituzionale ${ }^{29}$. Tale risultato fu conseguito mediando tra le due influenze culturali preminenti nella storia di Cuba: quella del diritto costituzionale spagnolo - nella fattispecie rappresentata dal Tribunal de garantías constitucionales della seconda Repubblica spagnola- e quella nordamericana, che esercitò una "presencia perturbatora" nelle vicende politiche e istituzionali dell'isola, anche oltre il periodo dell'occupazione durato sino al $1902^{30}$.

\section{LA COMPLESSA DIFFUSIONE DEL MODELLO "AUSTRIACO" IN AMERICA LATINA}

Il riferimento all'esperienza austrica da parte di molti ordinamenti dell' America latina fu mediato dal processo di ibridazione che tale sistema subì nel corso delle successive ondate costituenti che interessarono l'Europa: il controllo accentrato dapprima ispirò le Costituzioni italiana (1948) e della Repubblica federale tedesca (1949); quindi, alla fine degli anni '70, contemporaneamente alla formazione di regimi democratici, vennero istituiti Tribunali costituzionali in Spagna e in Portogallo. Né va trascurato come la giustizia costituzionale sia approdata anche in ordinamenti che, come la Francia e il Belgio, avevano contra-

\footnotetext{
Bassols Coma, 33.

28 Vedi: García Balaunde, 2000: 125; Fernández Segado, 2002: 669; Menéndez Menéndez, 1945.

29 Si veda: García Balaunde 2000: 140.

30 Così, García Balaunde, 2000: 129.
} 
stato, anche sul piano teorico, tale forma di controllo di costituzionalità delle $\operatorname{leggi}{ }^{31}$.

In Italia, il controllo di costituzionalità, una volta entrato in funzione, ha accentuato progressivamente i profili di concretezza del giudizio costituzionale attraverso l'introduzione di punti di contatto tra sistemi accentrati e diffusi, tra modelli astratti e concreti. Infatti, l'organo competente a decidere è unico (come nel prototipo austriaco), però ciascun giudice può partecipare al processo costituzionale (come nella judicial review); inoltre, lo stretto legame che unisce la decisione della Corte al "caso" che ha generato il processo si associa alla natura "astratta” del giudizio finale, dal momento che il processo è comunque finalizzato a espellere dal diritto positivo, con decisioni aventi valore erga omnes, le norme contrarie alla Costituzione ${ }^{32}$.

Nella Repubblica federale di Germania i costituenti innovarono rispetto alla tradizione tedesca del secolo XIX che aveva optato per un controllo di costituzionalità di natura non giurisdizionale ${ }^{33}$. In seguito all'approvazione della Costituzione del 1949 fu attivato uno specifico organo giurisdizionale specializzato in controversie costituzionali e parte integrante del "potere giurisdizionale": il sindacato sulle leggi poteva essere promosso o da un giudice nel corso di un processo (come in Italia) ovvero da un organo costituzionale ricorso astratto promosso (come in Austria) ${ }^{34}$. Inoltre, fu potenziato il suo ruolo di garante del carattere democratico dell'ordinamento, avendo la competenza a dichiarare la perdita di diritti fondamentali nei confronti di chi abusa di alcune libertà costituzionali per combattere l'ordinamento federale democratico o a decidere sull'incostituzionalità dei partiti che, tentando di pregiudicare o eliminare l'ordinamento democratico, minacciano l'esistenza della Repubblica federale tedesca.

In Spagna, poi, la Costituzione democratica del 1978 rompe con una tradizione che aveva attribuito la competenza a vegliare sul rispetto della Costituzione, di volta in volta, al Parlamento (Costituzione di Cadice), al Senato (progetto di Costituzione federale del 1873), al Consiglio del Regno (Anteprogetto della Costituzione monarchica del 1929): i costituenti furono, infatti, favorevoli ad allineare la natura e le competenze del Tribunal Constitucional alle esperienze italiana e della Repubblica federale di Germania, piuttosto che del Tribunale sulle garanzie costituzionali della Seconda Repubblica.

Uno dei caratteri più evidenti del sistema spagnolo di giustizia costituzionale è individuabile nell'ampiezza delle attribuzioni assegnate al Tribunale, al punto che uno dei più autorevoli giuristi lo qualificò come "la justicia constitucional

\footnotetext{
Pegoraro, 2019; Luther et alt., 2000; Fernández Rodríguez, 2007.

Gardino, 1988; Luciani, 1984; Cappelletti, 1957; Catelani, 1993.

33 La Costituzione del secondo Reich del 1871, ad esempio, affidava la competenza in materia di controversie costituzionali al Bundesrat, mentre la competenza a giudicare la conformità del diritto statale a quello federale era affidata al Reichsgericht. Vedi: Jellinek, 2013.

34 Ortino, 1966; Lanchester, 1985; Cerrina Ferroni, 2002.
} 
más amplia que existe sobre la tierra" ${ }^{35}$. Tale valutazione, in effetti, non pare eccessiva qualora si consideri sia la molteplicità delle sue competenze (controllo legittimità degli atti aventi forza di legge, protezione diretta dei diritti fondamentali, soluzione dei conflitti costituzionali, controllo preventivo dei trattati internazionali, delle leggi organiche e degli Statuti di autonomia, tutela dell'autonomia locale), sia la pluralità dei soggetti competenti ad adire al Tribunale costituzionale (Difensore del popolo, Ministerio fiscal, un certo numero di parlamentari, il Governo nazionale e delle Comunità autonome, l'autorità giudiziaria, i cittadini nei ricorsi di amparo) $)^{36}$.

Gli esempi sopra richiamati testimoniano esperienze in cui l'attivazione di forme "ibride" di giustizia costituzionale è avvenuta immediatamente dopo l'entrata in vigore di ordinamenti democratici, ispirati allo Stato sociale di diritto: mentre in altri paesi l'introduzione di forme di giustizia è concretizzata con ritardo, dopo aver superato diverse perplessità: è il caso, ad esempio, della Francia, del Belgio e del Portogallo ${ }^{37}$.

Lo stretto legame tra giustizia costituzionale e carattere democratico della forma di Stato caratterizza anche la realtà dell'America latina, dal momento che l'istituzione di Tribunali costituzionali ispirati alle esperienze europee ha il suo pieno sviluppo nella fase del c. d. nuovo costituzionalismo latino americano, con la crisi di sistemi autoritari e l'affermazione di ordinamenti democratici, ispirati allo Stato sociale di diritto. Siffatta coincidenza non è casuale in quanto evidenzia il legame che unisce tre caratteristiche del costituzionalismo contemporaneo come il principio di legalità, la garanzia dei diritti fondamentali e la giustizia costituzionale.

L'accentramento dell'esercizio della giustizia costituzionale si è realizzato in America latina sostanzialmente in tre modi: riservando tale competenza alla Corte Suprema nel suo pleno, a una sua Sala constitucional o istituendo un apposito Tribunale costituzionale esterno al potere giudiziario.

La prima soluzione fu adottata, ad esempio, in Venezuela ove il pleno della Corte Suprema de Justicia esercita un controllo oggettivo sulla costituzionalità delle leggi e degli atti aventi forza di legge attraverso una acción popular e intemporal, mentre le Salas de Casación Civil o Penal decidono come giudici di ultima istanza in materia di inapplicazione nei casi concreti delle leggi e degli atti con

35 García de Enterría, 1984.

36 Rubio Llorente y Aragón Reyes, 1982; Almagro Nosete, 1980; Villaroya, 1978; Francisco Segado, 1984; García de Enterría, 1981, 35.

Per quanto riguarda la prima dottrina italiana relativa al Tribunale costituzionale spagnolo si veda: Rolla, 1986.

37 Sul difficile percorso della giustizia costituzionale in Francia: Favoreu y Philippe, 2005; Zanon, 1990; Gambino, 1988; León Alonso, 2012: 10; Catalano, 2016; Benvenuti, 2016.

Con riferimento al Belgio: Carozza, 1985. Per riferimenti generali relativi al Portogallo si rinvia a: Vagli, 2001. 
forza di legge lesivi dei diritti costituzionali. Anche in Messico la revisione costituzionale del 1994 ha attribuito alla Suprema Corte de Justicia de la Nación en pleno la competenza di dichiarare con effetto generale la perdita di vigenza degli atti normativi di carattere generale attraverso una sentenza adottata a maggioranza qualificata (art. 105. II) ${ }^{38}$.

A Panama, la Corte Suprema de Justicia esercita un controllo di costituzionalità avente a oggetto non solo le leggi e gli atti aventi forza normativa, ma anche gli atti amministrativi con effetti nei confronti dei singoli; mentre in Uruguay la Costituzione del 1989 assegna alla Corte Suprema de Justicia la giurisdizione esclusiva per dichiarare l'incostituzionalità delle leggi e degli atti aventi forza di legge per vizi sia sostanziali che formali (art. 256).

Altri ordinamenti latinoamericani hanno optato, invece, per un controllo accentrato esercitato da una Sala specializzata della Corte Suprema de Justicia.

In Colombia l'affidamento a un giudice speciale del controllo di costituzionalità è piuttosto recente e l'evoluzione del sistema ha seguito un percorso poco lineare. Dapprima la Costituzione del 1886 attribuì alla Corte Suprema di Giustizia una competenza di natura preventiva sui progetti di legge del Parlamento; mentre, nell'anno successivo, fu escluso ogni sindacato successivo disponendo - con la legge n.153 del 1887- che ogni disposizione di legge successiva alla Costituzione deve essere applicata "aun cuando parezca contraria a la Constitución". Inoltre, la riforma costituzionale del 1910, nel mentre ha riconosciuto ai cittadini il diritto di presentare un'azione di incostituzionalità avverso leggi e decreti ritenuti contrari alla Costituzione, ha rotto l'unitarietà del controllo di costituzionalità riservando alla giurisdizione amministrativa la competenza a decidere sulla costituzionalità dei decreti non aventi forza di legge.

Soltanto nel 1968 un'ulteriore riforma costituzionale ha istituito all'interno della Corte Suprema una Sala costituzionale con una limitata competenza di natura istruttoria (predisporre una bozza di decisione da sottoporre alla valutazione dal plenum della Corte); mentre la Costituzione del 1999 ha introdotto due novità importanti: la prima assegna a tutti i giudici il compito "de adecuar la integridad de la Constitución en el ámbito de sus respectivas competencias" (art. 334) e di decidere sui ricorsi di amparo a tutela dei diritti e delle garanzie costituzionali (art. 27). La seconda, a sua volta, qualifica la Sala constitucional come" máximo y último intérprete de la Constitución" con l'obiettivo di assicurare una "uniforme interpretación y aplicación" della stessa (art. 335) ${ }^{39}$.

In Costa Rica, la Sala Constitucional de la Corte Suprema de Justicia dichiara la incostituzionalità di tutti gli atti normativi dello Stato —compresi quelli dei privati che esercitano funzioni pubbliche- che violano, por acción u omisión, le norme e i principi costituzionali (art. 73, Ley de la Jurisdicción Constitucional de 1989): sono, tuttavia, esclusi dal sindacato gli atti giurisdizionali del potere

38 Occorre il voto di almeno 8 componenti su 11.

39 Herrera Andrade, 2011: 97. 
giudiziario $^{40}$. Diversamente, in Paraguay la Sala Constitucional de la Corte Suprema de Justicia decide sulle azioni o eccezioni che, con riferimento a un caso concreto, lamentano la incostituzionalità delle leggi e degli altri atti normativi: tuttavia, la sua decisione ha effetti non erga omnes, ma riferiti al caso concreto (art. 260.1) ${ }^{41}$. Anche in Honduras la Ley sobre la Justicia Constitucional del 2004 ha disciplinato l'esercizio di un'azione di incostituzionalità innanzi alla Sala costituzionale della Corte Suprema da parte di un soggetto titolare di un interesse "personal, legítimo y directo" 42 .

Infine, in Salvador, la Sala costituzionale della Corte Suprema de Justicia esercita il controllo accentrato di costituzionalità in virtù di una triplice competenza: decidere sui ricorsi di incostituzionalità presentati dai cittadini nei confronti delle leggi, degli atti aventi forza di legge e dei regolamenti; risolvere i ricorsi di amparo per violazione dei diritti costituzionali e quelli di habeas corpus contro ogni restrizione illegale della libertà personale sollevati da qualsiasi individuo.

Tuttavia, la Sala costituzionale non è l'unico organo di giustizia costituzionale: infatti il suo controllo accentrato è accompagnato dalla competenza dei Tribunali della Repubblica di disapplicare, nei casi concreti sottoposti alla loro giurisdizione, norme contrarie alle disposizioni costituzionali; così come i Tribunali di seconda istanza possono risolvere i ricorsi di habeas corpus ${ }^{43}$.

Le soluzioni precedentemente individuate hanno cercato di innestare il controllo accentrato di costituzionalità all'interno della tradizione giuridica del continente latinoamericano, dando vita ad un sistema misto; altri ordinamenti, invece, hanno preferito istituire un organo exnovo esterno al potere giurisdizionale, specificamente preposto a "la última salvaguarda de los valores y principios constitucionales frente a los poderes constituidos actuando siempre desde criterios y parámetros jurídicos” ${ }^{\$ 4}$.

Questa innovazione -introdotta in Bolivia, in Ecuador, in Cile, in Perùha prodotto una soluzione di continuità nella storia latinoamericana dei controlli costituzionali.

Nel periodo dell'Indipendenza, l'ordinamento boliviano, su influenza del pensiero liberale francese, aveva individuato nel Consiglio di Stato l'organo competente a esercitare il sindacato di costituzionalità; successivamente (dal 1861 al 1994) si consolidò un forma di judicial review che aveva la sua cuspide nel ruolo della Corte suprema di Giustizia, finché successivamente si optò per un controllo concentrato esercitato da un Tribunale costituzionale. In particolare, la Costituzione del 2009 ha qualificato l'attività del Tribunale costituzionale plurinazionale come "predominantemente concentrado y plural de constitucionalidad": infatti, in

\footnotetext{
Piza Escalante, 2004; Hernández Valle, 1997: 539; Pedro Sagüés, 1991: 471.

Silvero Salgueiro, 2007: 361.

Brewer Carías, 2005: 57.

Solano, 2007: 339.

44 Così: Aguiar de Luque, 1997: 21.
} 
base all'art. 196 Cost. questo organo possiede il monopolio nell'annullamento delle norme infracostituzionali incompatibili con la Carta costituzionale ${ }^{45}$, mentre decide in via di appello contro i ricorsi di amparo a tutela dei diritti e delle garanzie costituzionali ${ }^{46}$.

Anche in Ecuador le prime Carte costituzionali avevano individuato nel Consiglio di Stato l'organo competente a velar por el respeto de la Costitución, segnalando — di volta in volta - le possibili violazioni all'Asamblea Nacional (1851), al Potere esecutivo o ai Tribunali (1906). Inoltre, in seguito alla riforma costituzionale del 1919, il Consiglio di Stato esercitò anche un controllo preventivo nel corso dell'iter legis. Successivamente, con la Costituzione del 1945, il controllo di costituzionalità fu affidato a un organismo specializzato -il Tribunal de Garantías Constitucionales - non pienamente autonomo dal potere politico, che poteva formulare osservazioni sui progetti di legge, nonché sospendere (su richiesta di giudici di ultima istanza) la vigenza di atti normativi con una decisione che, tuttavia, non era definitiva dal momento doveva essere confermata dal Congresso Nazionale.

Soltanto con la riforma costituzionale del 1996 fu istituito un Tribunale costituzionale, al cui interno la competenza è ripartita tre Salas - competenti rispettivamente in materia di habeas corpus, di habeas data e di controllo di costituzionalità degli atti amministrativi-, mentre al plenum è riservato il controllo delle leggi e degli atti di legge, la risoluzione dei conflitti di competenza insorti tra gli organi costituzionali, nonché la possibilità di presentare proposte di riforma della Costituzione ${ }^{47}$.

In Cile, anteriormente al colpo di Stato dell'11 settembre 1973, il Tribunale costituzionale era concepito eminentemente come organo di meDíazione politica: il suo compito principale consisteva nel giudicare la costituzionalità dei decreti legge, risolvere i conflitti tra legislativo ed esecutivo inerenti all'interpretazione del testo costituzionale o nel verificare la legittimità del potere del Presidente della Repubblica di indire un plebiscito o di sciogliere il Congreso. La Costituzione del 1980 accentuò la natura politica del controllo costituzionale, esercitando —ad esempio - un controllo preventivo sulle leggi, su atti politicamente rilevanti del Presidente della Repubblica e dichiarando l'incostituzionalità di movimenti o partiti politici.

Inoltre -anteriormente alle successive revisioni costituzionali- la Costituzione aveva prodotto una sorta di "disseminazione" della funzione di garanzia costituzionale, in coerenza con la previsione dell'art. 6 Cost. secondo "cui los órganos del Estado deben someter su acción a la Constitución y a las normas dictadas

45 Non solo le leggi, ma anche gli statuti di autonomia, le leggi organiche, i decreti e tutte le decisioni di natura non giudiziale Vedi, gli Artt. 72 e 73 del Código Procesal Constitucional del 2012.

46 Fernández Segado, 2002; Rivera Santiváñez, 2009.

47 Morales Tobar, 2005: 237; Rivera Santiváñez, 2009. 
conforme a ella" ${ }^{38}$. Nel valutare la qualità del sistema non va, tuttavia, trascurato che, nonostante la molteplicità dei controlli, su tutto il sistema delle garanzie costituzionali si proiettava l'ombra del ruolo istituzionale delle Forze Armate, rispetto al quale non pare improprio parlare di omnipresencia castrense y poder paralelo ${ }^{49}$.

Solo con la riforma costituzionale del 2005 si delinea un più coerente sistema di giustizia costituzionale che, da un lato, ha accentrato nel Tribunale costituzionale la pienezza delle competenze in materia di costituzionalità delle leggi (sia preventive che successive) e, dall'altro lato, ha trasferito a questo organo alcune attribuzioni in precedenza riservate alla Corte Suprema (tra cui i conflitti di competenza tra le autorità amministrative e giurisdizionali $)^{50}$.

Anche in Perù, il riconoscimento della supremazia della Costituzione nei confronti delle altre fonti del diritto avvenne con un significativo ritardo: $\mathrm{i}$ documenti costituzionali del 1860, del 1867 e del 1920 non avevano esplicitamente collocato le norme costituzionali al vertice del sistema delle fonti del diritto; inoltre, la Costituzione del 1933 optò —in controtendenza con altri ordinamenti dell'America latina - per un tradizionale meccanismi di difesa politica della Costituzione, secondo il quale le eventuali infrazioni potevano essere denunciate davanti al Congresso.

Soltanto nella Costituzione del 1979 fu introdotto un Tribunal de Garantías Constitucionales, ma la mancanza di un'adeguata tradizione giuridica inflù̀ negativamente sull'operato di questo organo: esso non solo non riuscì a emanciparsi dai legami di dipendenza dagli organi politici, ma produsse anche una giurisprudenza del tutto inefficace dal momento che il plenum, nell'affrontare questioni di particolare rilevanza istituzionale, non sempre conseguì il quorum necessario. Infine, con il colpo di Stato del 1992 il Tribunal de Garantías Constitucionales venne sciolto.

Anche l'esperienza del Tribunale costituzionale, istituito nel 1993, si rivelò tribolata, poiché tale organo si trovò inizialmente nell'impossibilità di funzionare con regolarità a causa sia del ritardo con cui fu approvata la Legge organica sul Tribunale costituzionale (1995), sia dell'impossibilità di decidere con il plenum dei suoi componenti ${ }^{51}$.

48 Basti considerare che la Corte suprema, d'ufficio o su ricorso di parte, poteva dichiarare inapplicabili ai casi concreti le norme di legge contrarie alla Costituzione (art. 80 cost.); mentre, a sua volta, la Contraloría general de la República esercitava il controllo di costituzionalità sui decreti legge e sugli atti dell'amministrazione, e controllava la legalità dell'azione amministrativa (art. 88 cost.). I problemi di costituzionalità relativi alla materia elettorale rientravano, invece, nella competenza del Tribunal Calificador de Elecciones (art. 84).

49 Rolla, 2001: 1084

50 Sulla giustizia costituzionale in Cile: Nogueira Alcalá, 1997: 539 y 1995: 111; Ríos Álvarez, 2007: 243; Zapata, 2011; Zúñiga, 2005; Gómez, 1996: 3.

51 Se nel 1996 furono nominati dal Congresso i sette giudici costituzionali, nell'anno successivo tre magistrati vennero destituiti impedendo così al Tribunale di esercitare il 
A conclusione di questo paragrafo non si può trascurare l'impostante trasformazione che ha interessato il ruolo della Corte Suprema del Messico. Essa con la sua giurisprudenza ha fatto compiere all'ordinamento costituzionale messicano un salto di qualità nel processo di integrazione all'interno del sistema interamericano di garanzia dei diritti fondamentali, aprendosi a una prospettiva multilivello ${ }^{52}$; inoltre, ha favorito il formarsi di una vera e propria "giurisdizione costituzionale delle libertà" facendo evolvere l'istituto dell'amparo attraverso l'ampliamento dei diritti tutelabili e del suo oggetto ${ }^{53}$.

Nello stesso tempo, la Corte Suprema, agendo in sintonia con il legislatore, ha posto le basi per rideterminare il "modello" messicano di controllo di costituzionalità, al punto che in dottrina si è sviluppato il dibattito se la Corte Suprema si sia trasformata progressivamente in un Tribunale costituzionale ovvero conservi ancora la sua posizione di cuspide del sistema giudiziario ordinario. Il Tribunale costituzionale, sotto il profilo formale, è un organo esterno sia al potere legislativo che a quello giurisdizionale, autonomo e fornito di spiccati requisiti di imparzialità e di professionalità; inoltre il suo procedimento possiede delle peculiarità connesse alla specificità del giudizio che lo differenziano dalla giurisdizione ordinaria. Invece, i profili sostanziali di tale organo possono essere individuati nella differenza esistente tra sindacato di legalità (o convenzionalità) e di costituzionalità. Alla luce di queste premesse si può rispondere all'interrogativo se la Corte Suprema sia o meno un Tribunale costituzionale indicando che essa (al momento) svolge "compiti analoghi" a quelli di una Corte costituzionale vera e propri: infatti, alcune competenze sono assimilabili a quelle dei Tribunali costituzionali, mentre altre sono proprie delle Corti di cassazione come giudici di ultima istanza sulle questioni di legalità ${ }^{54}$.

controllo sulle leggi. Soltanto nel 2000, con il ritorno alla democrazia, si è avuta la reintegrazione dei tre magistrati mancanti.

In materia si veda: García Balaunde, 1989; Blume Fortini, 1996; Cáceres Arce, 2004.

52 A conferma di questa valutazione si può richiamare che il premio per i Diritti Umani dell'ONU per l'anno 2013 fu assegnato alla Suprema Corte de Justicia de la Nación con la seguente motivazione: "Esta Corte ha logrado importantes progresos en la promoción de los derechos humanos a través de sus interpretaciones y de la aplicación de la Constitución mexicana y sus obligaciones bajo el derecho internacional de los derechos humanos asimismo ha fijado importantes estándar de derechos humanos para México y la región latinoamericana”.

In dottrina: Tron Petit, 1997: 143; González Pérez, 2013: 199; Sandal Ramos Koprivitza, 2016; Teutli Otero, 2013: 523.

53 Comprendendo anche le norme generali, le omissioni e gli atti nono solo delle autorità pubbliche, ma anche dei privati che agiscono in modo autoritativo, esercitando una funzione prevista dalla legge. In dottrina: Ferrer Mac-Gregor y Sánchez Gil, 2013; Fernández Fernández y Samaniego Behar, 2011: 173; Cruz Angulo Nobara, 2017: 173; Herrera García, 2015: 153.

54 Rientrano tra le prime, soprattutto, il giudizio di amparo in caso di lesione delle garanzie costituzionali; i giudizi costituzionali diretti di revisione delle sentenze dei tribunali federali; 
Siffatto avvicinamento a forme di giustizia costituzionale concentrata è avvenuto secondo un percorso a tappe, puntando sull'incremento progressivo dell' istituto dell'amparo e sull' ampiamento delle funzioni della Corte Suprema: nel primo caso, è stato rilevante sia il consolidamento del principio secondo cui i ricorsi potevano avere a oggetto anche le sentenze giudiziali, sia il riconoscimento che il juicio de amparo potesse avvenire anche nei confronti delle leggi e delle fonti primarie lesive di diritti costituzionali. Con riferimento all'aumento delle competenze in materia costituzionale della Corte Suprema, le riforme costituzionali del 2011-2003 hanno rafforzato una tendenza favorevole all'introduzione di procedimenti di controllo astratto e concentrato, dando vita a un sistema "misto" che opera secondo due livelli autonomi e separati, che funzionano parallelamente.

In ambito statale il potere giudiziario esercita un controllo di convenzionalità exofficio per verificare se la normativa nazionale sia compatibile con la Costituzione federale e le norme internazionali così come interpretate dalla Corte Interamericana. L'ambito federale, invece, si caratterizza per un controllo accentrato esercitato dal Poder Judicial della Federazione cui si ricorre in via diretta attraverso le azioni di incostituzionalità, le controversie costituzionali e gli amparo. Si introduce, quindi, un sistema che si basa sulla convivenza tra un sindacato concentrato e uno diffuso che agiscono parallelamente; anche se, in caso di contrasto, compete alla Corte Suprema determinare quale sia l'interpretazione costituzionalmente corretta ${ }^{55}$.

Un impulso decisivo nel caratterizzare le funzioni della Corte Suprema come materialmente costituzionali si è avuto, dapprima, in seguito alla creazione dei Tribunales Colegiados de Circuito, che si era resa necessaria per "liberare" l'attività della Corte dal crescente numero dei ricorsi di amparo; quindi, a causa di un deciso ampliamento delle loro attribuzioni in materia di controllo di legalità e di fonti secondarie: il che ha consentito alla Corte Suprema di concentrarsi sui profili di costituzionalità e le questioni di maggior "trascendencia"

Siffatta evoluzione ha sicuramente rafforzato l'idea che il potere giudiziario fosse la miglior garanzia per la salvaguardia della Costituzione e dei diritti fondamentali; così come la giurisprudenza della Corte Suprema ha saputo svolgere un ruolo fondamentale nelle più recenti fasi di cambiamento, orientando un sistema politico e istituzionale si apriva a nuove sfide. Con la sua attività, ha saputo conseguire un consenso attorno al suo ruolo di garante della regolarità costituzionale:

le azioni di costituzionalità che hanno l'obiettivo generale di preservare la primazia delle norme costituzionali attraverso un controllo sulla validità di leggi, decreti, regolamenti e trattati internazionali; le controversie costituzionali con le quali la Corte Suprema, affrontando conflitti che i soggetti politici non sono stati in grado di comporre, è competente sulle controversie tra la Federazione, gli Stati e i municipi o l'esecutivo e il Congresso, tra i poteri delle entità federative e tra gli organi di governo del Distretto federale.

55 Mac-Gregor y Silva García, 2011; Carnota, 2011: 51; Kastilla, 2011: 59; Sánchez Gil, 2012; Magaloni, 2011.

56 Acuña, 2020: 74. 
in quanto interprete privilegiata della Costituzione può rendere le disposizioni costituzionali un corpo vitale (un living tree) in sintonia con le trasformazioni sociali e del costume.

\section{IL RUOLO DEI TRIBUNALI COSTITUZIONALI NELLE TRANSIZIONI DEMOCRATICHE E IL RAPPORTO CON IL PASSATO}

A partire dalla seconda metà del secolo scorso molti ordinamenti costituzionali sono stati interessati da un processo di democratizzazione in seguito all'approvazione di Costituzioni che hanno segnato un elemento di rottura o di forte discontinuità rispetto al passato.

Alla fine del secondo conflitto mondiale l'Italia e la Germania hanno approvato delle carte costituzionali accomunate da alcuni caratteri omogenei: la posizione centrale assegnata al riconoscimento dei diritti fondamentali dell'individuo, il rafforzamento degli istituti propri dello Stato di diritto, la giustiziabilità di tutti gli atti delle pubbliche autorità e un controllo di legittimità costituzionale sugli atti normativi. Inoltre — anche sulla base dell'incapacità manifestata dalla Costituzione di Weimar e dallo Statuto albertino a frenare l'affermazione di regimi totalitari- i due ordinamenti hanno rafforzato il carattere rigido della Costituzione: sia ponendo limiti materiali all'attività di revisione costituzionale e strumenti di autodifesa del carattere democratico dell'ordinamento, sia codificando un netto giudizio di ripulsa nei confronti delle drammatiche esperienze vissute $^{57}$.

Differente fu, invece, la transizione costituzionale in Spagna, Portogallo e Grecia, dove il ritorno alla democrazia avvenne con modalità sostanzialmente pacifiche e pattuite: in questi paesi l'acquisizione delle libertà fondamentali e la ricostituzione di istituzioni democratiche si saldarono con la volontà di procedere a un'opera di riconciliazione nazionale, mentre le varie componenti della società e dello Stato presero parte alla transizione democratica. In Spagna, l'esercito (tranne alcuni infruttuosi tentativi) non ostacolò nel complesso il superamento dell'assetto autoritario e tale processo ebbe anche l'appoggio dell'istituzione monarchica ${ }^{58}$; in Portogallo, furono proprio i militari a prendere l'iniziativa per sostituire il precedente regime ${ }^{59}$; mentre in Grecia le forze armate accettarono le nuove regole democratiche e sostennero il primo presidente post dittatura ${ }^{60}$.

57 Come il divieto di riorganizzazione del partito fascista in Italia e la decadenza dal godimento di alcuni diritti fondamentali per coloro che si propongono di combattere l'ordinamento fondato sui principi di libertà e di democrazia in Germania.

58 Sulla transizione politica in Spagna, vedi: De Otto Pardo, 1977; Maravall, 1982; Hernández Gil, 1982; Attard, 1983; Morodo, 1984; Díaz, 1987; Jiménez Campo, 1981.

59 Costa Pinto, 2006; Maxwell, 1995.

60 Varsori, 2010: 10. 
Un processo politico simile ha interessato anche il continente americano, determinando una vera e propria cesura sia rispetto alla fase dell' indipendenza e al costituzionalismo liberale, sia soprattutto alla più recente e traumatica storia del continente, contrassegnata dall'instaurazione di regimi totalitari ${ }^{61}$. Sotto il profilo delle procedure costituzionali si è assistito a un'attività costituente pactada finalizzata ad aumentare la legittimazione delle scelte costituenti ${ }^{62}$; mentre per quanto concerne il valore della Costituzione si è passati dal derecho político al derecho constitucional, con l'introduzione di appositi organi e procedure.

In sintesi, pare corretto affermare che le principali codificazioni costituzionali che si sono succedute a partire dalla seconda metà del secolo xx hanno espresso una visione alternativa rispetto al passato circa i valori che debbono ispirare la società e ai principi che organizzano il funzionamento dello Stato, proponendosi di favorire la formazione di un nuovo humus sociale e politico ${ }^{63}$.

Tanto le Costituzioni approvate al termine di una profonda rigenerazione politica e sociale, quanto quelle che hanno concluso una transizione democratica o pactada hanno dovuto "fare i conti" con il proprio passato, anche se questo tema è stato affrontato secondo una prospettiva differente.

Le Costituzioni europee che hanno codificato una netta rottura rispetto al passato hanno manifestato un esplicito rifiuto delle precedenti, drammatiche esperienze totalitarie: si va dalla codificazione dell'improponibilità dei regimi passati (come in Italia ove la Costituzione vieta la ricostituzione del partito fascista e la revisione della forma repubblicana, intesa in senso sostanziale quale formula espressiva dei principi supremi in cui si riconosce l'ordinamento costituzionale italiano), alla codificazione di disposizioni che vietano o impediscono, pur nell'ambito di un ampio riconoscimento del pluralismo politico e della libertà di manifestazione del pensiero, la possibilità di comportamenti propri dei precedenti regimi autoritari (come in Germania, ove l'art. 18 della Legge fondamentale priva del godimento di alcuni diritti fondamentali chi intende abusarne, ciò̀ utilizzarli al fine di combattere una societàà libera e democratica). Inoltre esse

61 Mezzetti, 2002: 589; Biagi, 2016; Carducci, 1999; Alcántara Sáez, 1999.

62 Basti considerare, a titolo di esempio, il Pacto de los olivos in Argentina, celebrato nel 1993 tra i presidenti delle due forze politiche maggioritarie, che servì da base per la riforma costituzionale del 1994; l'accordo tra le autorità governative e i gruppi guerriglieri che favorì la promulgazione della Costituzione colombiana del 1991 e la revisione costituzionale del 1991 in El Salvador; il patto tra gli oppositori al governo militare che favorì la riforma costituzionale del 1988 in Brasile. Mentre in Ecuador e in Cile furono i militari gli arbitri del processo costituente. In Ecuador essi nominarono due commissioni di giuristi con il compito di elaborare ciascuna una progetto di Costituzione; il corpo elettorale attraverso un referendum fu chiamato a scegliere tra le due proposte; mentre in Cile la revisione costituzionale, dopo le dimissioni del dittatore Pinochet, fu attentamente monitorata dalle istituzioni militari, presenti nei principali organi costituzionali.

63 Fa eccezione la transizione costituzionale del Cile dove gli elementi di continuità tra il regime dittatoriale e il nuovo ordine costituzionale furono molteplici. A proposito si rinvia a: Rolla, 2001: 576. 
hanno dedicato un'attenzione particolare nel rafforzare quei presidi democratici che nel passato erano stati strumentalmente utilizzati per favorire la crisi dei regimi democratici: si pensi, ad esempio, all'attenzione che le Costituzioni hanno dedicato agli istituti che possono consentire una sostanziale garanzia ai diritti fondamentali — che secondo l'art. 19 della Legge fondamentale non possono essere intaccati nel loro contenuto essenziale, mentre l'art. 2 della Costituzione italiana ne sancisce l'inviolabilità-; oppure al significativo rafforzamento degli istituti propri dello Stato di diritto o orientati a rafforzare il carattere rigido della Costituzione.

Nel caso, poi, del neocostituzionalismo latinoamericano il rapporto con il passato è stato affrontato in una duplice prospettiva. Da un lato, la reazione alle esperienze dittatoriali è avvenuta migliorando i caratteri democratici e sociali dell'ordinamento, potenziando i meccanismi di tutela dei diritti fondamentali e ampliando la gamma delle posizioni soggettive garantite, rafforzando il carattere rigido della Costituzione e disciplinando le possibilità di esercizio degli stati di eccezione $e^{64}$.

Dall'altro lato, si è cercato innovativamente di "fare i conti" con il retaggio del colonialismo storico e con i pericoli di nuove forme di colonialismo politico, economico e culturale.

Nell'America latina del XIX secolo le élite politiche che promossero i movimenti indipendentistici si impegnarono soprattutto a creare una identità nazionale ispirata ai principi del costituzionalismo liberale; di conseguenza, i documenti costituzionali di quel periodo trascurarono del tutto la peculiarità dei popoli indigeni (ampiamente presenti in tutti i territori) a favore di un'idea di comunità politica omogenea, al cui interno $\mathrm{i}$ componenti condividessero la medesima cultura e lingua; inoltre non mancarono nei singoli Stati particolari politiche di repressione e di negazione della presenza indigena.

Un netto salto di qualità nel modo di affrontare la tematica degli inherents rights delle comunità indigene si ebbe alla fine del secolo scorso con i processi di transizione democratica che caratterizzarono molte realtà dell'America latina. Gli esempi che si possono fare sono numerosi: la Costituzione del Nicaragua attribuisce alle comunità della Costa atlantica il diritto a sviluppare la propria identità culturale entro l'unità nazionale, a esercitare autonome forme di organizzazione sociale, amministrativa ed economica, a mantenere forme comunitarie di proprietà e di sfruttamento della terra ${ }^{65}$; l'art. 216 della Costituzione brasiliana obbliga lo Stato a promuovere e proteggere il cultural heritage di tutti i gruppi presenti sul territorio, mentre la Costituzione del Paraguay qualifica i popoli

\footnotetext{
64 Subsay, 2019; Guedán y Escobar, 2005; Alcántara Sáez, 2003: 206; Ceccherini, 2002; Mezzetti, 2000; Carducci, 1998.

65 Artt. 89-91.
} 
indigeni come gruppi culturali autoctoni, anteriori alla formazione dello Stato e riconosce la preminenza del diritto consuetudinario ${ }^{66}$.

La revisione costituzionale messicana del 2001 definisce, a sua volta, la Nazione come "pluriculturale", fondata originalmente dai popoli indigeni che discendono dalle popolazioni che abitavano il territorio prima della colonizzazione e che ancora conservano proprie istituzioni sociali, economiche, culturali e politiche ${ }^{67}$; e la Costituzione della Repubblica bolivariana del Venezuela del 1999 dedica un capitolo specifico ai diritti dei popoli indigeni, al pari della revisione costituzionale del 1994 dell'Argentina. A loro volta, le Costituzioni della Bolivia del $2009^{68}$, e dell'Ecuador del 1998 e del 2008 riconoscono uno status differenziale a favore dei popoli indigeni ${ }^{69}$.

Tuttavia, la disciplina probabilmente più completa è quella della Colombia: tra i diversi articoli della Costituzione che affrontano il tema dell' identità culturale dei popoli indigeni si possono richiamare l'art. 7 (tutela della diversità etnica e culturale della nazione colombiana), l'art. 10 (riconoscimento dell'ufficialità delle lingue indigene nei rispettivi territori), l'art. 246 (giurisdizione speciale indigena), l'art. 68 (promuove una formazione che sia rispettosa dell'integrità culturale dei popoli), l'art. 171 (riconosce ai popoli indigeni una circoscrizione elettorale specifica in modo da favorire la rappresentanza politica di quei territori), gli Artt. 329 e 330 (affermano il diritto inalienabile alla proprietà collettiva della terra e allo sfruttamento delle risorse presenti nei territori indigeni), l'art. 248 (attribuisce alle entità territoriali indigene autonomia amministrativa e di bilancio), infine l'art. 246 riconosce l'esercizio di specifiche funzioni giurisdizionali.

Fa eccezione al soprarichiamato orientamento costituzionale l'atteggiamento contrario assunto dal Cile, dal momento che - pur essendo stata approvata nel 1993 una Ley Indigena - manca in Costituzione un riferimento alla specificità

\section{Artt. 62 e 63.}

67 Art. 2.

68 La Costituzione della Bolivia riserva un capitolo specifico ai diritti delle nazioni e dei popoli indigeni, riconoscendo il diritto alla sopravvivenza, all'identità culturale, alle proprie "creencias religiosas, espiritualidades, prácticas y costumbres, y a su propia cosmovisión" (art. 30); mentre, l'art. 179 riconosce anche la giurisdizione speciale indigena esercitata dalle proprie autorità, la cui giurisdizione e effetti delle decisioni hanno lo stesso valore di quella ordinaria.

69 La Costituzione del 1998 riconosce i diritti dei popoli indigeni in quanto componenti di un Stato pluriculturale e multietnico: il diritto a conservare la propria identità e tradizioni, sviluppare le forme tradzionali di convivenza e organizzazione sociale, conservare la proprietà imprescrittibile delle terre comunitarie (arts. 83-85); mentre l'art. 191 riconosce alle autorità indigene l'esercizio della funzione giurisdizionale nelle forme previste dall'art. 191. A sua volta, la Costituzione del 2008 ridetermina all'art. 171 le forme di amministrazione della giustizia indigena. 
della situazione dei popoli indigeni e un giudizio negativo nei confronti delle politiche attivate nei confronti del territorio e delle popolazioni Mapuche $e^{70}$.

Dare effettività a questi innovative norme costituzionale è stato un compito che i Tribunali costituzionali assunsero con impegno; la loro giurisprudenza ha svolto nel corso di questo secolo un ruolo fondamentale non solo nel tutelare i diritti dei popoli indigeni, ma anche nell'individuare criteri utili a sistematizzare i caratteri essenziali di tali gruppi sociali. In questo contesto, assume - a nostro avviso- particolare importanza l'apporto della giurisprudenza costituzionale della Corte costituzionale della Colombia la quale, attraverso un'ampia giurisprudenza, ha individuato il nucleo essenziale dell'identità culturale delle popolazioni indigene in due elementi: il rapporto con uno specifico ambito territoriale e una visione olistica del mondo.

Essa ha riconosciuto che la diversità etnica e culturale è la proiezione sul piano giuridico del carattere democratico, pluralista e partecipativo dello Stato e che i gruppi indigeni si differenziano dalle altre comunità sociali per il fatto che non si è in presenza "della mera sommatoria di individui singoli accomunati da una serie di diritti e di interessi diffusi" ${ }^{71}$. Di conseguenza la titolarità dei diritti riconosciuto dalla Costituzione appartiene al soggetto collettivo (cioè alla comunità ancestrale) e si manifesto all'interno di un determinato ambito territoriale, ove la comunità è storicamente insediata.

Altri elementi qualificanti la personalità giuridica delle comunità indigene sono individuabili nella proprietà collettiva della terra e nella dimensione comunitaria della vita, che costituiscono elemento integrante della cosmovisione e della religiosità della comunità indigena ${ }^{72}$ : di conseguenza, ogni modificazione dei territori indigeni — come la realizzazione di infrastrutture o lo sfruttamento delle risorse naturali- non è ammissibile senza un'autorizzazione esplicita da parte delle comunità ${ }^{73}$.

Non dissimile è stato l'atteggiamento tenuto dalla Suprema Corte de Justicia del Messico nei confronti di alcuni ricorsi presentati dalla comunità indigena yaquis, la quale rivendicava il diritto a essere previamente ascoltata sui progetti di infrastrutture che riguardavano il loro territorio. ${ }^{74}$ Nello stesso senso, una decisione del Tribunale costituzionale peruviano ha accolto un ricorso di amparo presentato dalla Comunità nativa di Santa Clara a tutela dei propri

70 E' noto che nel periodo fra il 1860 e il 1883 il loro territorio fu occupato militarmente, che i terreni liberati furono messi a disposizione degli investitori stranieri o dei grandi proprietari, che gli indigeni furono confinati in riserve. Inoltre, durante il regime militare di Pinchet continuò l'espropriazione e la vendita dei loro territori; mentre l'esistenza di una questione indigena fu negata secondo l'idea che "No existen poblaciones indígenas, somos todos chilenos".

71 Sentenza C-063 del 2010.

72 Sentenze T 188 del 1993 e C 058 del 1994.

73 Sentenza T-257 del 1993.

74 Pasillas, 2018: 10. 
diritti ancestrali, evidenziando la speciale connessione che esiste tra il territorio e l'utilizzo delle risorse naturali necessarie per il suo sviluppo ${ }^{75}$.

La giurisprudenza dei Tribunali costituzionali ha messo a fuoco un altro istituto caratterizzante l'identità culturale delle popolazioni indigene, individuabile nel valore giuridico della giurisdizione indigena, competente a risolvere $\mathrm{i}$ conflitti interni alle comunità. Si tratta di un sistema giuridico speciale, derogatorio rispetto a quello ordinario, che si basa su costumi e pratiche ancestrali estranee alla tradizione giuridica del continente latinoamericano ${ }^{76}$. La giurisprudenza costituzionale, tuttavia, ha fissato alcuni limiti sostanziali ai quali il diritto indigeno si deve comunque attenere, come i principi costituzionali e l'ordine pubblico $^{77}$, oppure la tutela dell'eguaglianza tra i sessi, come affermato dalla Sala costituzionale del Venezuela ${ }^{78}$.

\section{L'APPORTO DEI TRIBUNALI COSTITUZIONALI PER CONFERIRE EFFETTIVITÀ ALLE NORME COSTITUZIONALI AMPLIANDO L'OGGETTO E IL PARAMETRO DEL SINDACATO DI COSTITUZIONALITÀ}

I Tribunali costituzionali, una volta entrati in funzione, hanno dovuto dare soluzione a due esigenze fondamentali: offrire, come interpreti privilegiati del significato delle disposizioni costituzionali, una visione delle scelte costituenti che sia in armonia con le trasformazioni sociali e culturali del paese e, contestualmente, acquisire una salda legittimazione sociale ed istituzionale. Nello stesso tempo, hanno dovuto realizzare uno spartiacque netto tra le nuove Costituzioni e gli ordinamenti giuridici precedenti e, a tal fine, hanno sopperito a limiti inerenti alla disciplina della giustizia costituzionale (come limitatezza delle competenze attribuite ai giudici costituzionali, scelte restrittive in materia di accesso al processo costituzionale, inadeguatezza della tipologia delle sentenze) con l'individuazione in via giurisprudenziale di tecniche interpretative e di metodi decisionali idonei ad allineare la normativa vigente ai nuovi valori costituzionali e a ridurre lo iato che intercorre tra le norme costituzionali e l'effettività del sistema

Auto del Tribunale constitucionale peruviano del 20 agosto del 2018.

76 Bengoa, 2000; Cammarata, 2006: 45; Sánchez, 1998; Ron, 2011; Vera Lugo, 2006: 205; Ortiz Quiroga, 2013: 217; Pineda Camacho, 1997: 107; Carrillo García y Cruz Carrillo, 2016: 235.

77 Sentenza T-254 del 1994 Corte costituzionale della Colombia.

78 In particolare, tale giudice ha individuato un limite sostanziale del diritto indigeno nella Ley Orgánica sobre los Derechos de las Mujeres a una vida Libre de Violencia, in base alla quale la competenza a decidere nei confronti di una donna è comunque riservata ai Tribunales de violencia contra la mujer e alla Sala de Casación del Tribunale Supremo (Sentenza n. 919 del 2014). 
normativo vigente. Non sono patrimonio specifico di singoli ordinamenti, ma hanno avuto la capacità di circolare tanto in Europa, quanto nella gran parte dei paesi dell'America latina, dando vita a una sorta di jus commune del diritto processuale costituzionale in fieri ${ }^{79}$.

In primo luogo, i giudici costituzionali hanno affermato la propia competenza ad annullare o a rendere disapplicabili le norme anteriori all'entrata in vigore della Costituzione non compatibili con essa: sul piano istituzionale si trattava di decidere se la competenza a non rendere più applicabile la normativa anteriore alla Costituzione dovesse essere riconosciuta al legislatore, ai giudici comuni o ai Tribunali costituzionali. Con riferimento, invece, alla teoria delle fonti del diritto, il dibattito costituzionale ha ruotato attorno all'interrogativo se dal contrasto normativo scaturisse una dichiarazione di incostituzionalità ovvero un effetto abrogativo: nel primo caso si sarebbe dinanzi a un casso di invalidità in base al principio di gerarchia; nel secondo, la norma risulterebbe valida, ma non più applicabile alle fattispecie future in coerenza con principio tempus regit actum.

In proposito i diversi ordinamenti hanno fornito risposte differenti, dando vita a scenari istituzionali diversi, ma non antagonistici: infatti, progressivamente le distanze tra gli orientamenti giurisprudenziali si sono attenuate pervenendo a risultati sostanzialmente omogenei.

Il primo scenario — riconducibile essenzialmente all'ordinamento costituzionale tedesco - ha individuato nell'organo rappresentativo (il Parlamento) il soggetto preposto — almeno nella fase iniziale — alla modernizzazione della legislazione, rendendola coerente con le nuove disposizioni costituzionali: l'obiettivo di tale scelta può essere ricondotto all'intenzione che i singoli giudici si sottraggano alla volontà del legislatore, non applicando una norma con l'argomentazione che è incostituzionale; inoltre, sembra prevalente la volontà di assicurare il principio della certezza del diritto, privilegiando la continuità giuridica dell'ordinamento anteriore ${ }^{80}$. In questo caso, il protagonismo dei giudici è circoscritto a due specifiche situazioni: la prima si determinava allorché il dubbio insorgeva sulla base di un ricorso diretto di incostituzionalità e in questo caso il Tribunale costituzionale poteva annullare la norma; la seconda è riconducibile all'art. 123 della Legge fondamentale della Repubblica federale di Germania il quale affida ai giudici la valutazione circa la compatibilità alla Costituzione delle norme legali che debbono applicare (con decisioni aventi effetto inter partes).

Il secondo scenario è riconducibile all'esperienza italiana, dove la Corte costituzionale, già in occasione della sua prima sentenza, dinanzi al "silenzio" della Costituzione sul punto specifico, ha accolto il criterio che in un sistema a Costituzione rigida le sue disposizioni debbono prevalere su tutte le leggi ordinarie ancora vigenti e operanti al momento in cui la questione di legittimità

79 Balaunde, 1999: 121 ; Ferrer MacGregor, 2008 y 2009: 267; Fix Zamudio, 1999: 89.

80 De Otto, 2010: 685. 
costituzionale è posta ${ }^{81}$. Affermando tale principio interpretativo —in difformità dalla posizione prospettata dall'Avvocatura dello Stato secondo cui l'istituto dell'illegittimità costituzionale opererebbe soltanto nei confronti delle leggi posteriori all'entrata in vigore della Costituzione - il giudice costituzionale ha accentrato a sé tale verifica; in tal modo, la Corte preferito assicurare un'interpretazione unitaria del testo costituzionale, evitando che il pluralismo si trasformi in "anarchia interpretativa" 82 .

Una preoccupazione simile ha indotto — alcuni decenni dopo-il Tribunale costituzionale del Cile ad affermare progressivamente la propria competenza esclusiva a dichiarare incostituzionali e inapplicabili le norme di legge "siano anteriori o posteriori alla Costituzione e alle sue riforme": ciò al fine di superare il crescente contrasto (dottrinale e giurisprudenziale) tra chi propugnava la disapplicazione delle norme anteriori da parte dei giudici e chi propendeva per una dichiarazione di incostituzionalità del giudice costituzionale ${ }^{83}$.

Il terzo scenario evoca un situazione intermedia ed è riconducibile, innanzitutto, al contesto spagnolo degli anni immediatamente seguenti alla transizione democratica. In tale ordinamento non è stato inizialmente possibile conseguire zi un orientamento omogeneo: alcuni autori distinguevano tra leggi successive alla Costituzione (di competenza del Tribunale costituzionale) e leggi anteriori (disapplicabili dai giudici comuni) ${ }^{84}$; un'altra impostazione aderiva, invece, alla soluzione adottata dalla Corte costituzionale italiana ${ }^{85}$. Mentre la prima giurisprudenza del Tribunale costituzionale ha perseguito una soluzione di compromesso introducendo il concetto di incostituzionalità sopravvenuta, lasciando ai giudici l'opzione tra disapplicare la normativa anteriore nel caso concreto o sollevare una questione innanzi al giudice costituzionale. Ad avviso di un'autorevole dottrina, la ratio di tale scelta sarebbe riconducibile all'intenzione di coinvolgere tutti i poteri pubblici nel "conformar su acción a la Constitución" 86.

Tuttavia, nell'esperienza concreta, tale soluzione, oltre a creare disarmonie tra gli interpreti, non ha conseguito l'obiettivo di valorizzare il ruolo dell'ordine giudiziario nel favorire una chiara cesura tra il nuovo e il vecchio ordinamento costituzionale: infatti, nel periodo immediatamente successivo all'entrata in vigore della carta costituzionale, le questioni di costituzionalità inerenti alle leggi precostituzionali sollevate dai giudici furono numericamente limitate e poco significative ${ }^{87}$.

Così in sentenza n. 1 del 1956.

Così: De Enterría, 1985; Mortati, 1958: 526; Crisafulli, 1957: 271.

83 Vedi sentenza n. 991 del 2009. In dottrina: Enríquez Viñas, 2017: 307; Vega y Zúñiga, 2006: 135.

84 Aragón Reyes, 1981: 183 ss.

85 Varela y Satrustegui, 1979: 59; Rolla, 1986.

86 Jiménez Campo y Azcona, 1979: 109.

87 Aragón Reyes, 1981: 185; Parejo Alfonso, 1981: 201; Pérez Tremps, 1985; Varela y Satrustegui, 1979: 59; Díez-Picazo, 1985: 147. 
Nella prassi il sistema ha, però, progressivamente valorizzato il ruolo centrale del Tribunale costituzionale, richiamandosi sia all'art. 163 Cost. —che impone all'autorità giudiziaria di sollevare la questione di costituzionalità dinanzi al Tribunale ogniqualvolta, nel corso di un processo, ritenga che la norma primaria da applicare sia contraria alla Costituzione; sia all'art. 35 della Legge organica sul tribunale costituzionale del 1977 che attribuisce ai giudici la possibilità di scegliere se disapplicare la norma (con effetto limitato al caso concreto) ovvero sollevare la questione innanzi al Tribunale costituzione (con effetti erga omnes). A sua volta, la giurisprudenza del Tribunale costituzionale ha circoscritto gli ambiti di discrezionalità del potere giudiziario precisando che debbono essere sollevate innanzi al giudice costituzionale soltanto le norme che "no son susceptibles de reconducir por vías interpretativas al marco constitucional", introducendo l'obbligo per i giudici di un'interpretazione conforme a Costituzione ${ }^{88}$.

In secondo luogo, la possibilità per i Tribunali costituzionali di sviluppare le potenzialità che $\mathrm{i}$ diversi ordinamenti hanno attribuito a questi organi — sintetizzabili nel favorire la legalità sostanziale del sistema normativo, assicurare la protezione dei diritti fondamentali e l'equilibrio tra i poteri, esercitare una garanzia dinamica del patto costituente in modo da renderlo in sintonia con le trasformazioni social, economiche e culturale della società - è stata agevolata dalla loro capacità di ampliare progressivamente il parametro del giudizio di costituzionalità. Ciò è avvenuto secondo un percoreso progressivo che si è sviluppato in tre tappe, più di natura temática che cronológica.

Dapprima, si è verificato un sostanziale allineamento dei Tribunali costituzionali nel riconoscere la giustiziabilità di tutte le disposizioni contenute nel testo della Costituzionale, superando una tradizionale distinzione tra disposizioni precettive e meramente programmatiche (che pongono, cioè, obblighi nei confronti del solo legislatore). La portata precettiva di tutte le disposizioni costituzionali ha coinvolto, soprattutto, l'ambito dei diritti fondamentali, perché tale orientamento si contrapponeva ad alcune posizioni della dottrina, della giurisprudenza e a formule ambigue dei testi costituzionali ${ }^{89}$.

La prima, ad esempio, aveva distinto tra diritti di libertà —immediatamente azionabili- e diritti "condizionati", nel senso che il loro godimento dipenderebbe dalla quantità delle risorse disponibili, dalla presenza di un'organizzazione idonea ad assicurare l'erogazione di prestazioni che necessitano di una graduazione e di una meDíazione da parte dei pubblici poteri.

88 Si vedano, ad esempio, le sentenze n. 4 del 1981 e n. 14 del 1981. A proposito dell'interpretazione conforme nell'ordinamento spagnolo si veda: Rolla, 2010: 601.

89 Tra i molti autori si rinvia a: Cascajo Castro, 1988; Carmona Cuenca, 1992: 103; Ponce Solé, 2013; Canotilho Gomes, 2001; Abramovich y Courtis, 2002; Cascajo Castro, 2011; Peces-Barba Martínez, 1999; Pisarello, 2007; Terol Becerra y Jimena Quesada, 2014; Politi, 2018; Masala, 2014. 
Queste classificazioni trovano un'eco anche nella formulazione di alcuni testi costituzionali, i quali qualificano i diritti sociali, economici e culturali ricorrendo all'espressione duties (negli ordinamenti di ispirazione anglosassone), principios rectores (negli ordinamenti di tradizione ispanica) od obiettivi sociali (Svizzera): si tratta di qualificazioni che sono state interpretate come attribuzione ai poteri pubblici di un dovere di prestazione, quasi che i diritti sociali e culturali divengano esigibili nelle forme e nei contenuti individuati dalle politiche sociali intraprese dagli organi di indirizzo politico dello Stato ${ }^{90}$.

Anche la giurisprudenza ha considerato in diverse occasioni i diritti sociali come "diritti finanziariamente condizionati" qualità delle prestazioni sociali sono influenzate da alcuni fattori, come la quantità delle risorse disponibili, la condizione complessiva della finanza pubblica e i vincoli imposti dal contesto internazionale: di conseguenza il medesimo diritto (all'abitazione, all'istruzione, ai servizi sociali, al lavoro e a un salario dignitoso) contiene al proprio interno un set di prestazioni più ampio nelle fasi economicamente espansive oppure più circoscritto in situazioni di difficoltà economiche o di crisi del sistema di finanza pubblica. Comunque, le scelte legislative debbono sempre rispettare i principi di ragionevolezza e di proporzionalità e non intaccare il contenuto essenziale dei singoli diritti ${ }^{92}$.

In definitiva, la giurisprudenza dei Tribunali costituzionali si è progressivamente allineata, dopo alcune iniziali titubanze, nel riconoscere che anche i diritti che costituiscono principios rectores o finalità dello Stato sociale non sono delle mere disposizioni programmatiche, bensì costituiscono un parametro nei giudizi di legittimità costituzionale ${ }^{93}$. Un esempio emblematico di siffatta evoluzione giurisprudenziale può essere individuato in America latina nelle posizioni assunte dal Tribunale costituzionale del Perù.

Questo Tribunale sembrava orientato a inserire il diritto alla salute e alla sicurezza sociale tra quelli a "precettività differita", la cui garanzia non sarebbe di natura giurisdizionale, ma istituzionale ${ }^{94}$; di conseguenza, si tratterebbe di diritti pubblici soggettivi, di applicazione indiretta, che diventano giudizialmente esigibili a partire dalla loro configurazione legale ${ }^{95}$. Tuttavia, lo stesso giudice costituzionale, in decisioni successive, ha qualificato alcuni diritti sociali come una diretta proiezione del principio costituzionale della dignità dell'uomo ${ }^{96}$.

90 Per contro, l'art. 1, 3 c. della Legge fondamentale della Repubblica federale di Germania afferma che i diritti contenuti nel titolo I vincolano il potere legislativo, il potere esecutivo e quello giurisdizionale in quanto diritto immediatamente efficace.

Così: Merusi, 1990.

Rolla, 2020.

Così: García de Enterría, 1985.

94 Sentenza 11 del 2002. Per un'analisi organica della sua giurisprudenza si veda: Espinosa et alt., 1985: 68.

95 Sentenza 1417 del 2005.

96 Sentenza n. 8 del 2003. 
Ad esempio, ha affermato che in sede giurisdizionale non si può prescindere dal verificare se sia assicurata la dignità dell'uomo sia da parte dell'attività dello Stato che dei singoli ${ }^{97}$; così come, in altre sentenze, ha orientato la futura attività del legislatore indicando alcuni livelli essenziali di protezione che la legge deve comunque prevedere per non violare tale principio: ad esempio, in tema di educazione pubblica ha formulato un elenco di attività che la normativa in materia deve regolare ${ }^{98}$, mentre in materia di diritto alla salute ha estratto dalla normativa in materia alcune prestazioni che costituiscono il nucleo essenziale del diritto ${ }^{99}$.

In secondo luogo, il controllo di costituzionalità si è potuto giovare di un ulteriore parametro "implicito" rappresentato dai principi costituzionali, cioè danorme non scritte, ricavabili da un'analisi sistematica del testo costituzionale, che si pongono "al di sopra" delle singole disposizioni e rappresentano un limite sostanziale per il legislatore sindacabile dal giudice costituzionale ${ }^{100}$. L'utilizzo dei principi da parte delle giurisdizioni costituzionali può coinvolgere sia i principi istituzionali (riconducibili ai postulati dello Stato democratico di diritto), sia quelli inerenti alla materia dei diritti fondamentali i quali, a differenza di questi ultimi che possono essere limitati, e in alcuni casi — costituzionalmente disciplinati- anche temporaneamente sospesi, rappresentano un valore assoluto, che non può essere in alcun caso intaccato.

I principi espressi dalle Costituzioni democratiche scaturite dalle recenti transizioni costituzionali sono tutti riconducibili alla posizione di centralità che occupa la persona umana e alla sua intrinseca dignità. Va, tuttavia, precisato che la persona richiamata dai testi costituzionali non è l'individuo isolato, ma considerato nella sua proiezione sociale: il che amplia il novero dei diritti riconosciuti come fondamentali, comprendendo tutte le manifestazioni che si richiamano al principio personalista ovvero al libero sviluppo della persona. Non casualmente, i preamboli codificati nel nuovo costituzionalismo dell'America latina, i cui preamboli hanno individuato nella forma di Stato democratica l'assetto istituzionale più idoneo per assicurare la primazia della persona umana, le libertà ad essa collegabili e la sua dignità.

Di conseguenza, la giurisprudenza costituzionale ha utilizzato in modo proficuo come parametro di giudizio il principio di eguaglianza e di dignità per rafforzare la garanzia dei diritti sociali e culturali. Il primo consente di offrire a tutti i cittadini quelle parità di opportunità che la società, in ragione della sua struttura, non è in grado di predisporre autonomamente: autorizza, quindi, il legislatore a dettare condizioni di favore per tutti i soggetti che, per motivi economici o sociali, sono ostacolati o impediti nell'esercizio paritario dei diritti

\footnotetext{
Sentenza n. 8 del 2003.

98 Sentenza n. 4232 del 2004.

99 Sentenza 2480 del 2008.

100 In dottrina: Modugno, 2000: 95.
} 
costituzionali (la donna rispetto all'uomo, il lavoratore nei confronti del datore di lavoro, gli emarginati rispetto agli strati sociali meglio inseriti).

A sua volta, il principio della dignità dell'individuo codifica un valore universale che riguarda tutti gli individui indipendentemente dal loro status di cittadinanza e dalla traiettoria del loro percorso di vita ${ }^{101}$ e la sua applicazione riverbera effetti in una triplice direzione: offre al singolo una tutela processuale, autorizza il legislatore a limitare l'esercizio di attività suscettibili di produrre una menomazione della dignità degli individui, impegna i poteri pubblici a sviluppare politiche coerenti e in grado di stimolare comportamenti sociali virtuosi ${ }^{102}$.

A sua volta, l'esigenza di assicurare la maggior protezione possibile dei diritti umani ha spinto i giudici costituzionali a inserire nel parametro del controllo di costituzionalità anche $\mathrm{i}$ Trattati internazionali in materia di diritti umani e la conseguente giurisprudenza delle Corti sovranazionali: tali fonti hanno formato, insieme alle disposizioni costituzionali nazionali, un "bloque de constitucionalidad" al quale i giudici locali si debbono attenere, disapplicando le norme statali contrarie.

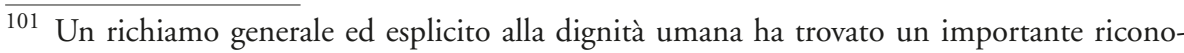
scimento in numerose Dichiarazioni internazionali in materia di diritti: dall'art. 1 della Dichiarazione universale dei diritti umani del 1948 (tutti gli esseri umani nascono liberi ed eguali nella dignità e nei diritti) all'art. 11.1 della Convenzione americana dei diritti umani del 1969 (ogni persona ha diritto al rispetto del suo onore ed al riconoscimento della sua dignità), all'art. 1 della Carta dei diritti fondamentali dell'Unione (la dignità umana è inviolabile. Essa deve essere rispettata e tutelata). Si può anche richiamare la Convenzione di Oviedo approvata dal Consiglio di Europa del 1999, la quale individua tra le sue finalità quella di prendere le misure necessarie per garantire la dignità dell'essere umano.

Ilrichiamo alla dignità della persona è presente nella quasi totalità delle carte costituzionali dell'America Latina: nell'art. 33 della Costituzione de la Costa Rica che proibisce "discriminaciones contrarias a la dignidad humana"; nell'art. 1 della Costituzione del Perù secondo il quale" la defensa de la persona humana y el respecto de su dignidad son el fin supremo de la sociedad y del Estado"; nell'art. 6 della Costituzione della Bolivia e nell'art. 2 della Costituzione di Porto Rico, le quali affermano che la libertà e la dignità della persona sono inviolabili ed è dovere primordiale dello Stato rispettarle e proteggerle; nell'art. 1 della Costituzione del Brasile, nell'art. 5 della Costituzione del Nicaragua e nell'art. 3 della Costituzione del Venezuela, che pongono la dignità della persona umana tra i fondamenti dello Stato democratico di diritto; nella Costituzione della Colombia, che inserisce, all'art. 1, la dignità umana tra i principi fondamentali dello Stato e riconosce, all'art. 15, il diritto di ogni persona alla propria intimità personale, familiare ed al suo buon nome; nell'art. 23 della Costituzione dell'Ecuador e nell'art. 68 della Costituzione dell'Honduras, i quali riconoscono il diritto fondamentale all'integrità personale, vietando ogni comportamento degradante per la persona; nell'art. 2 della Costituzione del Guatemala, che garantisce "el desarollo integral de la persona"; nell'art. 1 della Costituzione del Messico, il quale vieta ogni discriminazione finalizzata ad attentare contro la dignità umana.

102 Si veda in generale: Rolla, 2012: 1077. 
I sistemi costituzionali, infatti, risentono della progressiva osmosi che si realizza tra sistemi nazionali e sovranazionali: si tratta di un fenomeno che esprime la tensione universalistica che anima la protezione della persona umana e certifica, in un mondo sempre più integrato, la crisi di autosufficienza degli ordinamenti nazionali. Sotto il profilo sostanziale, tale tendenza favorisce una certa omogeneizzazione dei livelli di tutela, offre al diritto nazionale la possibilità di specificare e di implementare i diritti riconosciuti nei singoli ordinamenti, favorisce la creazione di un diritto "comune" capace di costituire la base unitaria per la tutela dei diritti fondamentali in un determinato ambito geografico.

Rilevanti risultano anche le conseguenze sul piano dell'interpretazione e della configurazione costituzionale dei diritti: basti considerare, ad esempio, che i diritti riconosciuti dalle Costituzioni nazionali debbono essere interpretati anche alla luce delle omogenee disposizioni presenti nelle codificazioni sovranazionali $\mathrm{e}$ in conformità con l'interpretazione fornita dalle giurisdizioni internazionali; mentre, nel caso di posizioni soggettive non esplicitamente regolate dal diritto nazionale, $\mathrm{i}$ diritti riconosciuti in ambito sopranazionale possono essere direttamente applicabili nell'ordinamento interno.

Infine, un progressivo avvicinamento del significato da attribuire alle disposizioni dei diversi documenti di rango costituzionale è favorito — sotto il profilo sostanziale - dalla circolazione dei principi giurisprudenziali e - dal punto di vista delle tecniche ermeneutiche- dalla necessità di ricercare un'interpretazione conforme. In definitiva, la progressiva integrazione tra il sistema nazionale e quello sopranazionale fa sì che la giurisprudenza sovranazionale non rappresenti soltanto "valiosos criterios hermenéuticos" ${ }^{103}$, ma costituisca un imprescindibile strumento di aggiornamento del significato dei diritti tutelati, nonché di armonizzazione dei metodi e dei criteri interpretativi ${ }^{104}$.

Di conseguenza, le giurisdizioni nazionali escono da un sistema chiuso di protezione dei diritti, a favore della formazione di una giurisdizione costituzionale dei diritti in cui ciascun giudice deve ricercare un idem sentire in materia di diritti fondamentali.

L'apertura a una prospettiva multilivello ha caratterizzato la giurisprudenza di diversi Tribunali supremi: la Sala costituzionale della Costa Rica ha motivato con una certa frequenza le sue decisioni in conformità a quanto stabilito dalla giurisprudenza internazionale. Mentre un orientamento consolidato della Corte suprema dell'Argentina sostiene che le disposizioni della Convenzione sono gerarchicamente superiori alle norme interne e vincolanti per i tribunali: tale

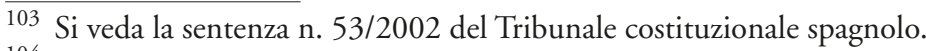

104 A proposito della protezione multilivello dei diritti fondamentali si veda, tra i molti: Bilancia y De Marco, 2004; Gambino, 2009; Butturini, 2009; Sciarabba, 2008.

Inambito americano si vedano i contributi di: Brewer Carias, 2006, 29; Hernández Valle, 2010: 73; Fix-Zamudio, 2006: 1727; Méndez y Cox, 1998; Navia, 1993; Eguiguren Praeli, 2003: 157. 
vincolo, ad esempio, ha indotto la Suprema Corte a dichiarare incostituzionali le c. d. leggi di "punto finale" e di "ubbidienza dovuta" (e privato di ogni effetto giuridico ogni atto fondato sulle stesse) sulla base dell'argomentazione che ogni regolazione di diritto interno che, invocando ragioni di "pacificazione", disponga il conferimento di qualunque forma di amnistia che lasci impunite violazioni gravi ai diritti umani perpetrate dal regime al quale la disposizione beneficia, è contraria a chiare ed obbligatorie disposizioni di diritto internazionale ${ }^{105}$.

Particolarmente evoluta appare, in proposito, la recente giurisprudenza della Corte Suprema del Messico.

Già prima della riforma costituzionale del 2011, la dottrina aveva interpretato la formula dell'art. 133 della Costituzione del 1917 nel senso che la Costituzione federale, le leggi del Congresso e i Trattati internazionali ratificati costituivano un "bloque de constitucionalidad" al quale i giudici locali si dovevano attenere, disapplicando le norme statali contrarie ${ }^{106}$. In tempi più recenti anche la Corte suprema si è allineata a tale impostazione e con crescente frequenza ha richiamato nelle motivazioni delle sue sentenze norme in materia di diritti umani ricavate dai Trattati internazionali e dalla giurisprudenza della Corte Interamericana dei diritti umani.

Ad esempio, ha risolto una controversia avente a oggetto la legittimità di una sanzione amministrativa che imponeva il lavoro obbligatorio, affermando la prevalenza della normativa internazionale che ammetteva il lavoro obbligatorio solo come conseguenza di una decisione dell'autorità giudiziaria ${ }^{107}$. In un'altra fattispecie, poi, sulla base di un confronto tra la normativa costituzionale e quella internazionale, ha affermato, in base al principio pro persona, il criterio interpretativo secondo cui, qualora non sia possibile armonizzare la normativa nazionale a quella sovranazionale, si deve applicare quella più favorevole al soggetto che ha presentato il ricorso ${ }^{108}$.

La Corte Suprema ha anche introdotto alcune importanti precisazioni a cui gli interpreti del diritto si debbono attenere. Innanzitutto, ha distinto tra $\mathrm{i}$ contenziosi internazionali in cui il Messico è parte processuale e quelli in cui non è direttamente coinvolto: nel primo caso, la giurisprudenza della Corte interamericana deve considerarsi vincolante, mentre nel secondo la ratio decidendi può essere utilizzata come un criterio orientatore.

105 Pizzolo, 2005; Bassionni, 2011.

106 Martínez Lazcano, 2019: 123.

107 Nell'Acción de Inconstitucionalidad n. 155 del 2007 ha fatto riferimento sia all'art. 8 del Patto internazionale dei diritti civili e politici, che all'art. 2 della Convenzione n. 29 dell'organizzazione internazionale del lavoro e all'art. 6 della Convenzione Interamericana dei diritti umani.

108 Si trattava della Controversia Constitucional n. 63 del 2011, relativa al dubbio se la revisione della Costituzione di Oaxaca, che aveva introdotto diversi istituti di democrazia diretta e di partecipazione popolare — nel caso specifico anche il cabildo abierto — avesse violato il diritto delle popolazioni indigene di essere preventivamente consultate. 
Inoltre la Corte, esercitando una funzione lato sensu didattica, ha precisato $\mathrm{i}$ procedimenti logici che i giudici debbono sviluppare nella soluzione delle diverse fattispecie, distinguendo tra l' interpretazione conforme in senso ampio (la normativa va interpretata in modo compatibile con i diritti costituzionali e quelli tutelati a livello interamericano), l'interpretazione conforme in senso stretto (tra diversi possibili significati di una disposizione si deve utilizzare quella conforme con la Costituzione e il Trattato Interamericano), mentre nelle situazioni in cui sia impossibile addivenire a una interpretazione conforme, i giudici debbono risolvere la questione de qua disapplicando la norma di legge.

Nella tesi 21 del 2011 la Corte Suprema ha affrontato l'interrogativo giuridico se la valutazione della compatibilità di una legge con un Trattato internazionale configurasse una "questione di costituzionalità" (e pertanto era possibile un amparo di revisione) ovvero una "questione di legalità", che avrebbe escluso l'esercizio di tale competenza: a suo avviso la questione deve essere risolta facendo riferimento alla materia oggetto del processo, nel senso che se essa coinvolge un diritto fondamentale si è in presenza di una questione di costituzionalità che potrà essere risolta in via definitiva dalla Corte Suprema, in caso contrario si è dinanzi a una questione di legalità, per cui le decisioni dei Tribunales Colegiados sono definitive e non impugnabili.

Da ultimo, la possibilità per i Tribunali costituzionali di ampliare le forme di tutela dei diritti fondamentali è stata favorita dalla diffusione di specifici istituti finalizzati a sanzionare l'inerzia del legislatore o delle pubbliche amministrazioni: in proposito, si registra un diverso orientamento tra gli organi di giustizia costituzionale europei e latinoamericani.

I primi — con alcune eccezioni come nel caso del Portogallo— ${ }^{109}$ preferiscono sopperire alle omissioni del legislatore ricorrendo a specifiche tecniche interpretative: in particolare, alle sentenze di incostituzionalità di tipo additivo, con le quali una disposizione è dichiarata incostituzionale non per quello che prevede, ma per quello che non prevede: in tal modo il giudice costituzionale introduce nell'ordinamento norme "nuove". In America latina, invece, si è preferito potenziare alcuni istituti processuali i quali, ispirandosi all'esperienza nordamericana del writ of mandamus, attribuiscono all'individuo che si ritenga leso in un proprio diritto a causa dell'inerzia del legislatore o della pubblica amministrazione la competenza a rivolgersi innanzi a un giudice affinché ordini all'amministrazione di provvedere e al legislatore a normare.

In Costa Rica, ad esempio, si può ricorrere davanti alla Sala Constitucional se la natura della omissione produce effetti diretti o viola interessi diffusi che interessano la comunità nel suo complesso; in Perù l'art. 200.6 Cost. ha introdotto la acción de cumplimiento da attivare ogni volta che i diritti costituzionali

109 In cui il Tribunale costituzionale adotta una decisione non vincolante, in quanto si limita a portare a conoscenza dell'organo competente la situazione di incostituzionalità prodotta dalla sua inerzia. 
vengono violati a causa di omissione di actos de cumplimiento obligatorio. La Costituzione dell'Ecuador, all'art. 436.10, attribuisce alla Corte costituzionale la competenza a dichiarare l'incostituzionalità per omissione nei confronti delle autorità pubbliche e degli organi dello Stato che non intervengono nei tempi previsti dalla Costituzione o in quello ritenuto ragionevole dalla Corte costituzionale. Mentre in Venezuela la Sala Constitucional del Tribunale Supremo può sia imporre al legislatore un tempo entro cui intervenire, sia indicare i caratteri generali dell'intervento ${ }^{110}$.

Infine, l'ordinamento costituzionale della Colombia differenzia le situazioni di mancata attuazione di una norma o atto amministrativo (acción de cumplimiento) dai casi in cui le omissioni assurgano a una particolare rilevanza di natura costituzionale (acción de tutela): nel primo caso è competente l'autorità giudiziaria; nel secondo, invece, la competenza spetta alla Corte costituzionale che, nella sua giurisprudenza, ha considerato omissione legislativa "todo incumplimiento por parte del legislador de un deber de acción expresamente señalado por el constituyente"111.

\section{IL RUOLO DEI TRIBUNALI COSTITUZIONALI NELLE FASI DI DEMOCRAZIA "MATURA". LA MOLTEPLICITÀ DELLE TECNICHE IDONEE A CONSENTIRE AI TRIBUNALI COSTITUZIONALI DI DIALOGARE CON GLI ATTORI DEL SISTEMA COSTITUZIONALE}

Nelle fasi di democrazia "matura" o consolidata l'oggetto dei giudizi di legittimità costituzionale non è più costituito dalla legislazione anteriore alla Costituzione, ma da leggi approvate recentemente. Questa premessa, apparentemente scontata, modifica profondamente il ruolo e l'azione della giustizia costituzionale: infatti, la giurisprudenza dei Tribunali costituzionali riflette, come uno specchio, la realtà sociale, con le sue contraddizioni e trasformazioni. Di conseguenza, aumenta il tasso di "politicità" delle decisioni, dal momento che i giudici debbono compiere un delicato lavoro di ponderazione, ricercando di volta in volta un equilibrio ragionevole tra le norme in gioco e tra queste e i principi supremi dell'ordinamento costituzionale. Attraverso il loro lavoro interpretativo i giudici costituzionali diventano artefici dinamici della integrazione sociale e garanti dell'unità sostanziale dell'ordinamento.

Attualmente, poi, è aumentata in misura considerevole la complessità delle questioni che i giudici debbono affrontare, dovendo compiere valutazioni non solo di stretto diritto, ma anche di natura scientifica, etica, economica; così come

$\overline{110}$ Vedi, con riferimenti specifici all'America latina: Díaz Revorio, 2001: 81; Fernández Segado, 2008: 13; Hernández Valle, 2006: 643; Nogueira Alcalá, 2003: 24; Sagüés, 2002: 605; Corrêa Souza de Oliveira, 2015: 34.

111 Sentenza del 16 ottobre 1996, C-543/96. 
appare complessa la ponderazione tra i diversi diritti in potenziale conflitto — tra la ricerca scientifica e i valori etici di un individuo, tra la libertà individuale e l'opinione pubblica. Altre questioni difficili da affrontare riguardano l'impatto che i processi di internazionalizzazione economica e finanziaria possono produrre sulla qualità dei sistemi nazionali di welfare e sulla fruizione dei diritti sociali.

Inoltre, il rapporto tra norme costituzionali e ordinamento si modifica: se durante le transizioni democratiche il giudice è chiamato a permeare l'ordinamento giuridico dei nuovi valori costituzionali, nei periodi di consolidamento democratico, invece, nella sua qualità di interprete privilegiato della Costituzione, deve trasformare le disposizioni costituzionali in un corpo vitale, in grado di porre il diritto in sintonia con le trasformazioni sociali, economiche e culturali.

Questa nuova funzione della giustizia costituzionale ha influito sulle tecniche di interpretazione, facendo oscillare il pendolo da un approccio di tipo originalistico a una progressiva adesione a teorie più dinamiche, che si ispirano all'idea di una living Constitution: la quale, fondandosi su di una distinzione concettale tra disposizione e norma, ha consentito di considerare il testo costituzionale "un living tree capable of growth and expansion within its natural limits"112.

Come è noto, le teorie "originaliste" furono elaborate nella fase immediatamente seguente all'entrata in vigore della Costituzione degli Stati Uniti d'America: lo stesso Jefferson aveva affermato che la Costituzione doveva essere interpretata d'accordo con l'intendimento "chiaro del popolo" degli Stati Uniti al momento della sua adozione ${ }^{113}$. Mentre in tempi più recenti, l'originalismo di tipo intenzionale — secondo cui il significato delle disposizioni è intrinsecamente legato all'intenzione espressa e voluta dagli autori del testo costituzionale - ha assunto un profilo prevalentemente ideologico, in contrapposizione all'attivismo interpretativo: in questo contesto, il richiamo alle intenzioni originarie dei padri fondatori si proponeva di limitare la discrezionalità dei giudici e di affermare la preminenza della volontà del legislatore rispetto all'interpretazione giudiziale della Costituzione ${ }^{114}$.

Molti autori hanno criticato tale impostazione sulla base di due fondamentali argomenti: per un verso, non è agevole stabilire le reali intenzioni collettive di chi ha approvato gli articoli costituzionali — specie se essi sono assai risalenti nel tempo-; per un altro verso, non sembra corretto utilizzare le originarie intenzioni dei costituenti per affrontare problemi contemporanei, inediti rispetto al momento genetico della fase costituente ${ }^{115}$.

112 Si rinvia a: Rolla, 2006: 10.

113 Bergh, 1907: 248.

114 Laise, 2017: 245; Scalia, 1997; Calabresi, 2008; Goldford, 2005; Huscroft y Miller, 2011; Strauss, 2010; Figueroa, 2000: 587; Verdugo y Francisco García, 2013: 137.

115 A questo proposito, è emblematico evidenziare l'atteggiamento della Corte Suprema del Canada, la quale si è chiaramente differenziata dalle teorie nordamericane dell' "original intent", ricordando che il Costitution Act ha il compito di guidare e servire il Canada per lungo tempo, accompagnando il processo di sviluppo delle istituzioni: di conseguenza 
Questo nuovo approccio ha inciso sia sul piano della teoria dell'interpretazione, sia sulle relazioni che intercorrono tra $\mathrm{i}$ diversi soggetti istituzionali chiamati a sviluppare "politiche" di attuazione costituzionale. Infatti, le Costituzioni, grazie alla struttura delle loro disposizioni e alla capacità interpretativa dei Tribunali costituzionali possono garantire una sintesi tra le norme e i valori contemporanei, tra il diritto e la storia: mentre il giudice costituzionale può porre il testo della Costituzione in sintonia le esigenze della contemporaneità, senza che si renda necessaria una sua modifica formale.

La giustizia costituzionale non è un potere isolato, estraneo al circuito delle decisioni politiche, ma interagisce, attraverso la propria giurisprudenza, con gli altri attori del sistema costituzionale; tale dialogo si manifesta sia adeguando le tecniche interpretative alle fattispecie concrete, sia instaurando una particolare relazione con il legislatore e la giurisdizione ordinaria.

Con riferimento alle tecniche decisionali, i Tribunali hanno affrontato la complessità delle questioni e la pluralità delle norme da contemperaresuperando l'alternativa tradizionale tra sentenze di accoglimento e di rigetto: infatti, i giudici costituzionali debbono spesso valutare la ragionevolezza delle scelte legislative e contemperare in modo equilibrato interessi e diritti contrastanti; così come non possono esimersi dal soppesare gli effetti delle proprie pronunce sull'ordinamento giuridico ${ }^{116}$. In tal modo, viene messa in discussione l'idea "kelseniana" che aveva accompagnato l'origine del modello "austriaco" secondo cui il Tribunale doveva operare come un "legislatore negativo".

Alcune decisioni sono funzionali a limitare gli effetti reatroattivi delle decisioni di incostituzionalità per ragioni di sicurezza giuridica (sentenze di illegittimità sopravvenuta); così come altre si propongono di ritardare gli effetti di una sentenza di incostituzionalità e consentire al Parlamento di intervenire con una nuova disciplina della materia o alle pubbliche amministrazioni di organizzarsi per meglio affrontare gli effetti della sentenza (sentenze di incostituzionalità differita). La ratio di questi tipi di decisione può essere individuata nell'intento di evitare un vuoto normativo che potrebbe generare gravi conseguenze alla coerenza dell'ordinamento giuridico.

Particolarmente diffuso è anche il ricorso alle dichiarazioni di incostituzionalità pro futuro sia in Europa — da parte del Tribunale costituzionale tedesco, della Corte costituzionale italiana e dal Tribunale costituzionale spagnolo ${ }^{117}$, sia in America latina, dove alcune normative abilitano i Tribunali a determinare gli effetti temporali delle decisioni di incostituzionalità: si pensi, ad esempio, alla legge

la Costituzione è redatta con lo sguardo verso il futuro e, quindi, deve essere capace di "growth and developpement over time to meet new social, political and historical realities often unimagned by its framers". In proposito, si veda: Iacobucci, 2004: 51.

116 Sul principio di ragionevolezza: Paladin, 1997: 899; Scaccia, 2000; Vipiana, 1993; D'andrea, 2005; Moscarini, 1996; Morrone, 2001.

117 Jiménez Campo, 1997; Politi, 1997; Ruggeri, 1988. 
1.836 relativa alla Corte costituzionale della Colombia, secondo la quale gli effetti delle sue sentenze "tienen efectos hacia el futuro a menos que la Corte resuelva lo contrario"; ovvero alla legge sulla Sala costituzionale della Corte Suprema del Venezuela, il cui art. 48.4 afferma che la decisione di incostituzionalità stabilirà "su dimensionamiento en el tiempo y los efectos sobre lo resuelto".

Sul piano giurisprudenziale si segnala l'orientamento della Corte costituzionale colombiana, la quale ha giustificato il ricorso a tali tipi di sentenze con la circostanza che l'annullamento di una norma può produrre, in determinate fattispecie, effetti incostituzionali o la lesione di altri principi costituzionali; mentre il Tribunale costituzionale del Perù ha adottatato sentenze in cui differisce gli effetti temporali della sua decisione, riconoscendo nel legislatore l'organo più idoneo a porre rimedio al vulnus di incostituzionalità ${ }^{118}$.

Diverso è, infine, il modo in cui il Tribunale costituzionale austriaco ha modulato gli effetti delle proprie decisioni: nella norma, le sentenze di costituzionalità hanno effetto abrogativo e producono effetti exnunc, mentre l'effetto retroattivo riguarda soltanto la questione che ha dato origine alla decisione del Tribunale; tuttavia, in alcune fattispecie, nel rispetto del principio generale di eguaglianza, tale effetto ha interessato anche tutti i giudizi in cui la magistratura ha utilizato la norma oggetto della decisione ${ }^{119}$.

Infine, i tipi di sentenze che producono effetti normativi possono essere classificati a seconda che esplicitino delle norme inespresse o introducano nuove norme.

Rientrano nel primo caso le sentenze interpretative che consentono al Tribunale costituzionale di individuare tra i significati ricavabili da una disposizione quelli che risultano compatibili o incompatibili con la Costituzione: in tal modo, il giudice costituzionale fa riferimento al principio di conservazione del diritto o di presunzione di costituzionalità degli atti normativi, evitando di annullare testi normativi che possono essere interpretati conformemente alla Costituzione.

Introducono, invece, norme "nuove" le sentenze di tipo additivo con le quali una disposizione è dichiarata incostituzionale in quanto non prevede una o più norme: in questo caso, il giudice delle leggi si trasforma in creatore di norme giuridiche al posto del Parlamento: tuttavia, tale sostituzione è giustificata dal fatto che, in alcune fattispecie, l'inserimento di una norma mancante costituisce l'unico modo per ripristinare la costituzionalità violata. Infatti, i Tribunali costituzionali ricorrono generalmente all'uso delle sentenze di tipo "additivo" per migliorare la protezione sostanziale dei diritti sociali o per evitare effetti discriminatori lesivi del principio di eguaglianza.

Queste tecnica, utilizzata in Europa, ha riscontrato un certo successo in America latina. A titolo di esempio possiamo richiamare alcune sentenze della

118 Nogueira Alcalá, 2004: 113.

119 Huppmann, 2000: 148 ss.; Schaffer, 1998: 148 ss. 
Corte costituzionale colombiana relative a disposizioni legislative che punivano con sanzioni economiche le persone che non presentavano puntualmente la propria dichiarazione dei redditi senza "permitir a la persona demostrar que el no cumplimiento del deber de presentar la declaración tributaria no le es imputable, por ser consecuencia de hechos ajenos a la voluntad, como el caso fortuito y la fuerza mayor" (sentenza C-690 del 1996), oppure che mancavano di una regolamentazione sistematica degli scioperi nei servizi pubblici essenziali (sentenza C-473 del 1994).

A sua volta, il Tribunale costituzionale della Bolivia ha dichiarato l'incostituzionalità per omissione di alcune disposizioni del Codice della sicurezza sociale che provocavano una discriminazione irrazionale e non proporzionale per motivi di sesso ${ }^{120}$; mentre il Tribunale costituzionale del Perù ha precisato che "los silencios constitucionales no pueden ser interpretados como tácitas concesiones al legislador, a efecto de que expida regulaciones desvinculadas de la Norma Fundamental ${ }^{121}$.

La duttilità delle tecniche interpretative utilizzate dai Tribunali costituzionali ha accresciuto la rilevanza del diritto giurisprudenziale, che interviene in funzione integrativa negli spazi lasciati liberi dalle fonti scritte.

Difficilmente l'interpretazione costituzionale è puro accertamento di norme, dal momento che le Costituzioni contengono spesso enunciati linguistici suscettibili di una pluralità di significati; di conseguenza, la frontiera "mobile" che separa l'applicazione dalla creazione del diritto non è rigida e comporta innovazioni nella sfera del diritto. Non a caso, alcuni ordinamenti hanno formalmente codificato il valore normativo della giurisprudenza inserendola tra le fonti legali del diritto ${ }^{122}$, mentre sono più frequenti $\mathrm{i}$ casi in cui la capacità normativa della giurisprudenza è la risultante di principi inerenti all'interpretazione giuridica.

\section{I TIPI DI SENTENZE FINALIZZATE A REGOLARE I RAPPORTI TRA I TRIBUNALE COSTITUZIONALI, IL PARLAMENTO E I GIUDICI}

Per i Tribunali costituzionali non è stato agevole conseguire un equilibrio tra le due "anime" che convivono all'interno della giustizia costituzionale: quella politica e quella giurisdizionale. L'"anima” giurisdizionale si manifesta soprattutto nei confronti delle relazioni che i giudici costituzionali stabiliscono attraverso le proprie sentenze con l'ordine giudiziario: per un verso, nei confronti dei giudici $a$ quibus - che sollevano, cioè, una questione di costituzionalità ovvero presentano un ricorso di amparo-, per un altro verso, con gli altri giudici, i quali debbono

120 Sentenza n. 62 del 2003.

121 Sentenza del 1 dicembre del 2003.

122 In Spagna, ad esempio, la giurisprudenza è annoverata tra le fonti legali del diritto (“completerá l'ordenamiento jurídico"). 
tener conto della giurisprudenza costituzionale allorchè debbono applicare in un caso concreto una determinata norma. In altri termini, si determina un continuum tra l'attività interpretativa dei giudici costituzionali e quella dei giudici comuni.

Nei rapporti con gli altri giudici, i Tribunali debbono "fare i conti" con la loro natura di giudici sui generis, i quali, pur decidendo sulla base di regole giuridiche, non sono del tutto estranei al circuito politico -istituzionale e svolgono un sindacato (di costituzionalità) che è parallelo a quello di legittimità proprio dei giudici ordinari. Inoltre, nel valutare la conformità alla Costituzione delle norme di legge, non possono trascurare l'impatto che le loro determinazioni producono non solo sull'ordinamento giuridico, ma anche nei rapporti con il Parlamento e il potere giudiziario. Come è stato efficacemente affermato, con la giustizia costituzionale si è introdotto "un terzo incomodo tra Potere legislativo e Potere

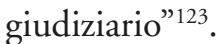

Dopo iniziali contrasti con le Corti supreme, si è in generale pervenuti a un ragionevole accomodamento, individuando regole condivise —rientranti, a nostro avviso, tra le convenzioni costituzionali- ${ }^{124}$ per limitare i conflitti interpretativi attraverso un dialogo tra le giurisdizioni. In primo luogo, si è riservata al giudice costituzionale l'interpretazione delle disposizioni costituzionali, riconoscendone il carattere vincolante per tutti gli operatori del diritto; mentre ai giudici comuni compete l'interpretazione delle norme secundum constitutionem e debbono rivolgersi ai Tribunali costituzionali solo nei casi in cui è impossibile pervenire a un'interpretazione costituzionalmente corretta.

Inoltre, i Tribunali costituzionali hanno progresivamente individuato peculiari tecniche interpretative, nuovi tipi di sentenze (le sentenze interpretative di rigetto e quelle correttive) e fissato alcuni criteri per ripartire i rispettivi compiti (in particolare, le nozioni di diritto vivente e di interpretazione conforme a Costituzione) $)^{125}$.

Le sentenze interpretative di rigetto regolano l'ambito all'interno del quale può manifestarsi l'autonomia interpretativa dei giudici comuni: esse, infatti, individuano, tra $\mathrm{i}$ possibili significati normativi che una disposizione può assumere, quello incostituzionale lasciando ai giudici la libertà di applicare tutti gli altri possibili significati. Con le sentenze correttive, a loro volta, i Tribunali costituzionali non decidono la questione sollevata dal giudice a quo, invitandolo a risolvere il proprio dubbio di incostituzionalità facendo ricorso a una interpretazione della disposizione a quo differente da quella iniziale. In questo caso, $\mathrm{i}$ giudici costituzionali affidano a quelli ordinari il compito di risolvere il contenzioso attraverso un'interpretazione secundum Constitutionem, lasciando intendere che ci si deve rivolgere al giudice costituzionale solo in caso di impossibilità di risolvere la questione ricorrendo a un'intepretazione costituzionalmente corretta.

123 Crisafulli, 1978: 74 .

124 Rescigno, 1972.

125 Gardino, 1988; Caretti y De Siervo, 2011; Mannella, 2011; Rolla, 2010: 1865. 
Inoltre, a mano a mano che si affinava il dialogo tra le giurisdizioni, si sono precisati meglio i rispettivi ambiti di competenza con l'obiettivo di assicurare i principi di sicurezza giuridica e di eguale applicazione del diritto. A tal fine l'esperienza comparata sembra aver raggiunto un punto di equilibrio attorno ad alcune acquisizioni convenzionalmente accettate: ad esempio, deve considerarsi riservata ai giudici costituzionali l'individuazione del significato delle disposizioni di rango costituzionale (il parametro), mentre è attribuita alla giurisdizione ordinaria la competenza a determinare il c. d. "diritto vivente", cioè il significato da attribuire alle fonti primarie alla luce di un' interpretazione giurisprudenziale consolidata e confermata dai Tribunali supremi ${ }^{126}$.

La ricerca di una interpretazione compatibile con le disposizioni costituzionali è un'operazione logica che compete a tutti gli operatori giuridici, ma in particolar modo ai giudici in quanto interpreti qualificati del diritto: utilizzando la formula dell'art. 5, $3 \mathrm{c}$ della legge organica spagnola sul potere giudiziario, si può affermare che i giudici possono sollevare la questione di incostituzionalità di una determinata disposizione soltanto "cuando por vía interpretativa no sea posible la acomodación de la norma al ordenamiento constitucional". Tuttavia, la funzione giurisdizionale deve, comunque, svolgersi nell'ambito della doctrina dei Tribunali costituzionali, le cui sentenze costituiscono delle vere fonti del diritto.

Nei confronti del legislatore, invece, i giudici costituzionali hanno, in genere, manifestato la preoccupazione di non interferire con la discrezionalità del Parlamento, dal momento che il controllo di legittimità costituzionale deve escludere ogni sindacato sull'uso del potere discrezionale del Parlamento e arrestarsi dinanzi alle c. d. "political questions": si tratta, in altri termini, di tracciare un limite tra discrezionalità politica e illegittimità costituzionale ${ }^{127}$. Anche in questo caso, per scongiurare un "corto circuito" tra politica e giurisdizione i Tribunali costituzionali hanno fatto ricorso a specifiche tecniche interpretative.

Talvolta, dovendo affrontare questioni controverse e dotate di un elevato tasso di politicità, hanno preferito che il vizio di costituzionalità fosse eliminato direttamente dal Parlamento con una nuova disciplina della materia, senza creare "vuoti" nel sistema normativo: in questi casi, le sentenze (attraverso obiter dicta) evidenziano i limiti della normativa impugnata, senza — però- annullarla. A tal proposito, un'autorevole dottrina ha utilizzato la nozione di reparación mediata, nel senso che il vizio di incostituzionalità viene rilevato dal giudice costituzionale, ma sanato dal successivo intervento del Parlamento, cui compete eliminare il vizio con una diversa disciplina della materia ${ }^{128}$.

Il dialogo con il legislatore diviene, poi, più sofisticato nel caso delle c. d. sentenze additive di principio, ove i termini della collaborazione con il legislatore

126 Si veda, ad esempio, la sentenza n. 356 del 1996 della Corte costituzionale italiana. In dottrina: Crisafulli, 1956: 929; Serra Cristóbal, 1999.

127 Sui rapporti con il legislatore: Passaglia, 2011; Aja, 1998.

128 Jiménez Campo, 1998: 121. 
risultano più precisi: il Tribunale costituzionale indica $\mathrm{i}$ criteri a cui bisogna rifarsi per evitare un vizio di incostituzionalità; al legislatore, invece, è affidato il compito di determinare, nella sua discrezionalità politica, i modi con cui dare attuazione agli indirizzi del Tribunale e trovare le relative coperture economiche. Le sentenze di indirizzo sono anche utilizzate nei casi in cui l'incostituzionalità è generata da una omissione o da una carenza della disciplina contenuta nella disposizione oggetto del giudizio ${ }^{129}$.

L' attività "monitoria" e di "indirizzo" dei giudici costituzionali è particolarmente diffusa. A titolo esemplificativo, si può evidenziare che Tribunale costituzionale tedesco ha introdotto una gamma assai articolata di strumenti perché il legislatore sani situazioni di incostituzionalità: in alcuni casi, precisa che la normativa è "ancora" costituzionale, ma suggerisce di revisionare la materia (in genere fissando anche un limite temporale); mentre in altre situazioni ha accompagnato il monito al legislatore con l'indicazione esemplificativa dei punti su cui intervenire ${ }^{130}$.

Una vasta eco ha suscitato in Italia una delle prime sentenza "monitorie" in cui il giudice costituzionale, in materia di sistema radiotelevisivo, ha dichiarato illegittimo non tanto il monopolio in sé, quanto le modalità con le quali esso era regolato da legislatore ed esercitato, provvedendo —altresì — a evidenziare i requisiti che avrebbe dovuto possedere la nuova disciplina della materia ${ }^{131}$.

In Spagna, a sua volta, la sentenza n. 36 del 1991 ha ricordato la imperiosa necessità di rivedere la disciplina a tutela dei minore chiedendo al legislatore di tener conto sia della giurisprudenza costituzionale, sia della Convenzione internazionale dei diritti del minore. Differentemente, nella sentenza n. 96 del 1996 in materia di enti di credito, il Tribunale costituzionale ha riconosciuto al legislatore un'ampia discrezionalità di configurazione normativa per riordinare la disciplina della materia nelle parti dichiarate non conformi alla Costituzione; mentre nella sentenza 45 del 1989 ha precisato al Parlamento che "esta tarea legislativa... debe ser llevada a término dentro de un plazo de tiempo razonable".

In America latina, infine, il Tribunale costituzionale cileno, dopo aver segnalato che alcuni punti specifici della materia non risultano sufficientemente regolati, ha invitato a tener presente "la necesidad de complementar, oportunamente, esta ley con las materias indicadas en los considerandos 11, 18, 19 y 25 de esta sentencia"132.

129 Parodi, 1996; Hernández Valle, 1997: 93.

130 Cerrina Feroni, 2002.

131 Come l'attività di indirizzo del Parlamento, l'esigenza di assicurare l'obiettività e la completezza dell'informazione, la garanzia del pluralismo in modo da esprimere le diverse istanze sociali, politiche, culturali e religiose della società. Vedi sentenza n. 225 del 1974.

132 Sentenza del 5 aprile 1988. 


\section{L'ACCENTUAZIONE DI NUOVE FORME DI "POLITICITÀ" DELLA GIURISPRUDENZA COSTITUZIONALE. VERSO UNA RIDEFINIZIONE DELLA NOZIONE DI POLITICAL QUESTION}

Se negli ultimi decenni del secolo scorso le tecniche interpretative adottate dai giudici costituzionali hanno decisamente superato l'impostazione originaria del controllo accentrato di costituzionalità austriaco, nel corso del XXI secolo sembra emergere un'ulteriore tendenza, che accentua la "politicità" del ruolo dei Tribunali costituzionali e amplia il loro coinvolgimento in contenziosi che inevitabilmente richiedono delle valutazioni di natura politica. Uno dei principi che il pensiero costituzionale liberale aveva individuato per introdurre uno spartiacque tra sindacato di merito e controllo di costituzionalità —il limite, cioè, delle political questions - presenta alcune crepe, nonostante la vigenza nelle Costituzioni di disposizioni che richiamano la separazione tra legislazione e giurisdizione: si pensi, ad esempio, all'art. III della Costituzione degli Stati Uniti d'America secondo cui la funzione giurisdizionale deve riguardare solo i casi di stretto diritto e di equità; oppure all'art. 28 della legge n. 87 del 1953 il quale precisa che il controllo della Corte costituzionale italiana esclude ogni valutazione di natura politica e ogni sindacato sull'uso del potere discrezionale del Parlamento.

D'altre parte — nella realtà contemporanea- questo confine si presenta abastanza poroso, dal momento che la linea che separa la politica dalla giurisdizione non è statica e il rispetto del confine dipende anche dall'attitude dei giudici costituzionali al self restraint. Inoltre, il rapporto della giustizia ostituzionale con le political questions è bivalente: per un verso, comprende la tendenza dei Tribunali costituzionali a decidere su questioni che prima si ritenevano non giustiziabili; per un altro verso, esprime la volontà dei poteri dello Stato di rendere tali organi partecipi di percorsi istituzionali di indubbia valenza politica.

A tale fine può essere utile richiamare due esperienze: la prima, in America latina, ha avuto ad oggetto il ruolo assunto dalla Corte costituzionale della Colombia nell'implementare e raccordare con le disposizioni costituzionali gli atti adottati dal Governo e dal Parlamento per porre termine alla guerriglia e alla forte instabilità del paese; la seconda, in Europa, si richiama alla rilevanza della giurisprudenza costituzionale nell'orientare il processo indipendentistico avviato dalla Comunità autonoma della Catalogna.

Con riferimento alla Colombia, la legge n. 975 del 2005 (conosciuta come la Ley de Justicia y Paz) recepì il negoziato tra il Governo e i gruppi paramilitari con l'obiettivo di favorire la smilitarizzazione dei gruppi paramilitari colombiani. Essa fondava la sua ratio sull'art. 22 Cost. in base al cale la pace era considerata un diritto e un dovere de obligatorio cumplimento e la sua attuazione necessitava di una delicata ponderazione tra diritti e principi costituzionali (diritto alla pace, riconciliazione, diritti al risarcimento, diritti alla verità e alla giustizia). La stessa Corte costituzionale ritenne necessario ottenere un equilibrio tra la necessità 
politica di conseguire la pace e l'esigenza costituzionale di proteggere i diritti delle vittime, evitando che si generasse una sorta di impunità di fatto ${ }^{133}$.

Nel corso del processo di pacificazione la giurisprudenza costituzionale ha perseguito - in generale - una linea di garantismo giurisdizionale che ha cercato di riequilibrare una visione plebiscitaria della democrazia portata avanti dal governo con il sostegno del Parlamento: siffatto indirizzo si è manifestato soprattutto in tre momenti importanti della vita politica della Colombiana presi in considerazione con le sentenze n. 551 del 2003 e n. 1040 del $2005^{134}$.

La prima sentenza aveva a oggetto il referendum proposto dal Governo, che aveva ad oggetto, una molteplicità di quesiti eterogenei — che spaziavano, ad esempio, dal limitare l'esercizio dei diritti politici per i corrotti alla penalizzazione del consumo di sostanze allucinogene, dalla limitazione salariale per dipendenti pubblici alla previsione di nuove risorse per l'educazione e la sanità. In via generale, il giudice costituzionale evidenziò la pericolosità di una consultazione popolare multitemática, dal momento che votare "in blocco" le singole proposte di riforma per trasformare l'istituto referendario in uno strumento plebiscitario, suscettibile di conculcare la libertà dell'elettore. Nella stessa sentenza, la Corte ha dichiarato l'incostituzionalità delle note introduttive al quesito dal momento la loro formulazione mancava di Neutralità e avrebbe condizionato la libertà di scelta degli elettori ${ }^{135}$.

Con la decisione 1040 del 2005 la Corte costituzionale, inoltre, ha riconosciuto la legittimità della revisione costituzionale (che disciplinava i modi di elezione del Presidente) approvata dal Parlamento: tuttavia, ha precisato come fosse necessario introdurre, tramite un'apposita legge, garanzie effettive per tutti i candidati. Tale sentenza è interessante in quanto il giudice costituzionale, nonostante la mancanza di limiti espliciti alla revisione costituzionale, ha ricavato da un'interpretazione estensiva dell'art. 241.1 della Costituzione il divieto di modificare il testo della Costituzione in un suo elemento essenziale: altrimenti, il legislatore eserciterebbe un potere costituente invece che costituito ${ }^{136}$. La Corte ha formato il proprio orientamento, applicando un test de sustitución in base al quale ha valutato se la legge di revisione contenesse principi opposti o integralmente differenti dagli elementi essenziali che costituiscono l'identità di una Costituzione.

133 Vedi, sentenza 370 del 2006.

134 Ruiz-Rico Ruiz, 125; Uprimny, 2006; Molinares Hassan, 2013: 29.

135 Il testo della nota introductoria: "para proteger la sociedad colombiana, particularmente su infancia y su juventud, contra el uso de cocaína, heroína, marihuana, bazuco, éxtasis y cualquier otro alucinógeno, ¿aprueba usted el siguiente artículo?”.

136 Tale articolo, dopo aver premesso che spetta alla Corte ostituzionale la tutela dell'integrità e delle supremazia della Costituzione, le attribuisce la competenza a decidere sulle richieste di incostituzionalità presentate dai cittadini contro atti di revisione della Costituzione per vizi relativi al procedimento. 
D'altra parte, il ruolo direttamente "politico" svolto dalla Corte costituzionale in questa travagliata fase della vita politica e sociale in Colombia emerge con chiarezza dalle stesse parole del Presidente della Corte, ad avviso del quale "la Corte hace un balance muy positivo de su rol en el proceso de paz, donde nos dieron una especie de rol como tercera Cámara, además de la Cámara de Representantes y del Senado, para revisar la implementación de ese proceso, que implicó un trabajo muy serio y responsable".

Se la Corte costituzionale della Colombia è intervenuta sulla sostanza del processo di pacificazione con la finalità di ricondurlo ai principi dello Stato di diritto e alla tutela dei diritti fondamentali, il Tribunale costituzionale spagnolo ha svolto una importante funzione di contrasto del processo secessionistico della Comunità catalana a salvaguardia della natura unitaria dello Stato.

Il tema dell'ammissibilità costituzionale dei processi di secessione ha inizialmente coinvolto ordinamenti di tipo federale ove il riconoscimento agli Stati membri di un "diritto" alla secessione ha lasciato progressivamente il campo alla individuazione di idonee procedure negoziate tra i soggetti istituzionali che compongono la Federazione ${ }^{137}$.

Più recentemente, il dibattito sulla necessità di tali procedure ha coinvolto anche sistemi regionali di common law: è il caso, ad esempio, del Regno Unito che ha affrontato le istanze di secessione cercando di armonizzare il principio costituzionale della sovereignty of Parliament con la consapevolezza che la decisione sostanziale debba comunque essere assunta direttamente dai cittadini dei territori interessati, sulla base di un processo politico non unilaterale, ma concordato ${ }^{138}$.

La particolarità del "caso" spagnolo è individuabile nella circostanza che non si sia verificato alcuno dei presupposti idonei ad avviare un "leale" processo di allentamento dei vincoli unitari: non solo è mancata una good faith negotiation, ma anche una "chiara maggioranza" a favore del processo di indipendenza espressa attraverso un referendum regolarmente convocato.

Il Tribunale costituzionale spagnolo ha dovuto affrontare essenzialmente tre tipi di questioni: l'uno inerente all'esistenza giuridica di un diritto del popolo

137 Si tratta, ad esempio, dei criteri indicati dalla Corte suprema del Canada che, nell'esercizio della sua competenza di reference, ha precisato che le aspirazioni alla secessione debbono, innanzitutto, essere certificate (attraverso un referendum) da una chiara maggioranza dei cittadini di quel territorio (clear majority), quindi, incanalate nell'alveo di procedure democratiche (good faith negotiations), condivise e giuridicamente regolate. Sull'influenza dell'esperienza canadese nel diritto comparato: Delledonne y Martinico, 2019.

138 Si consideri l'Accordo di Belfast del 1998 tra Regno Unito e Irlanda del Nord che menziona il diritto all'autodeterminazione tramite referendum degli abitanti nell'isola irlandese; mentre l'Accordo di Edimburgo del 2012 conferma questa regola costituzionale, riconoscendo che il futuro della Scozia all'interno del Regno Unito debba essere deciso dalla popolazione scozzese attraverso un referendum. 
catalano a decidir nella sua qualità di soggetto politico e giuridico sovrano; l'altro avente a oggetto i possibili modi di avvio di un iter politico finalizzato alla creazione di uno Stato indipendente e repubblicano. Il terzo, infine, concerneva l'ammissibilità di convocare con una legge della Comunità autonoma una consultazione popolare sul futuro politico della Catalogna.

Con la sentenza n. 42 del 2014, il giudice costituzionale spagnolo ha ribadito il principio secondo cui la titolarità di un potere sovrano spetta esclusivamente alla Nazione spagnola, non al popolo di una Comunità autonoma; di conseguenza, non è possibile convocare unilateralmente un referendum di autodeterminazione "para decidir sobre su integración en España”. A sua volta, la sentenza n. 259 del 2015 ha dichiarato l'illegittimità di una risoluzione del Parlamento regionale in quanto "en el Estado constitucional, el principio democrático no puede desvincularse de la primacía incondicional de la Constitución": di conseguenza, secondo il Tribunale costituzionale la volontà di indipendenza dovrebbe essere perseguita senza una "rottura" unilaterale del patto costituente, bensì seguendo le procedure legali di revisione della Costituzione ${ }^{139}$.

Queste pronunce del giudice costituzionale non sono state in grado di interrompere il processo politico-istituzionale concepito dagli indipendentisti catalani: cosicché il Tribunale costituzionale è intervenuto, negli anni successivi, con ulteriori 32 decisioni, utilizzando tutta la gamma di competenze processuali previste dalla Legge organica sul Tribunale costituzionale: dai ricorsi di costituzionalità ai conflitti di competenza, dall'impugnazione di disposizioni senza forza di legge a di risoluzioni delle Comunità autonome, da incidenti di esecuzione di sentenze costituzionali ai ricorsi di amparo ${ }^{140}$.

In tal modo il Tribunale costituzionale ha sviluppato con flessibilità il proprio orientamento di politica costituzionale, stigmatizzando sia una chiara violazione delle procedure parlamentari previste a garanzia delle minoranze, sia l'adozione di comportamenti lesivi di diritti dei cittadini catalani ${ }^{141}$. Infine, ha utilizzato le nuove competenze introdotte dalla legge organica n. 15 del 2015 per contrastare la "ribellione" degli indipendentisti nei confronti delle decisioni del giudice costituzionale: adottando autos esecutivi mirati a sospendere dalle loro funzioni autorità e impiegati pubblici, a irrogare sanzioni pecuniarie, ad annullare atti che contravvengano a decisioni anteriori del Tribunale o ingiungere di astenersi dall'adottare atti contrari alle decisioni del giudice costituzionale ${ }^{142}$.

139 Precisando che "la Constitución no es lexperpetua, sino que cabe la revisión total, y que la pueden solicitar las asambleas de las CCAA". Si veda: Castellà Andreu, 2016: 561.

140 De Miguel Bárcena, 2018: 133.

141 Sentenze n. 114, n. 121, n. 124, n. 139 del 2017.

142 Oltre agli autori sopra richiamati: Azpitarte Sánchez, 2018: 147; Ridao I Martín, 2014: 91; Barceló I Serramalera, 2016: 363; Matia, 2016. 


\section{Bibliografia}

Acuña, J. M. (2020). El parámetro de regularidad constitucional y la ley suprema de la Unión. Cuestiones constitucionales, 42, 74-101. Disponible en: https://doi. org/10.22201/iij.24484881e.2020.42.14337.

Aguiar de Luque, L. (1997). La justicia constitucional en Iberoamérica. Anuario Iberoamericano de Justicia Constitucional, 1, 22-32.

Aja, E. (1998). Las tensiones entre el Tribunal Constitucional y el Legislador en la Europa actual. Barcelona: Ariel.

Alcántara Sáez M. (1999). Sistemas políticos de América Latina. Madrid: Tecnos.

- (2003). De la democracia en América Latina al comenzar el siglo XXI. Quórum, 5-6, 206-220.

Almagro Nosete, J. (1980). Justicia constitucional. Madrid: Dykinson.

Andrews C. (2011). Los primeros proyectos constitucionales en México y su influencia británica (1821-1823). Estudios mexicanos, 27, 5-43. Disponible en: https:// doi.org/10.1525/msem.2011.27.1.5.

Annino, A. y Ternavasio, V. (2012). El laboratorio constitucional latinoamericano 1807/18081830. Madrid: Velvuerte. Disponible en: https://doi.org/10.31819/9783865279996.

Aragón Reyes, M. (1981). La sentencia del TC sobre las leyes relativas al régimen local anteriore a la Constitución. Revista Española de Derecho Constitucional, 1, 185-205.

Attard, E. (1983). La constitución por dentro. Barcelona: Argos Vergara.

Azpitarte Sánchez M. (2018). La defensa de la Constitución frente al secesionismo. Crónica política del año 2017. Revista Española de Derecho Constitucional, 112, 147-175. Disponible en: https://doi.org/10.18042/cepc/redc.112.05.

Barceló i Serramalera, M. (2016). El derecho a decidir como instrumento constitucional para la canalización de problemas territoriales. Fundamentos, 9, 361-391.

Bassionni, M. C. (2011). Crimes against humanity. Historical evolution and contemporary application. Cambridge University of Cambridge. Disponible en: https:// doi.org/10.1017/CBO9780511976537.

Bassols Coma, M. (1981). La jurisprudencia del Tribunal de Garantías constitucionales de la II República española. Madrid: Centro de Estudios Constitucionales.

Battaglini, M. (1957). Contributi alla storia del controllo di costituzionalità delle leggi. Milano: Giuffrè.

Bengoa, J. (2000). La emergencia indígena en América latina. Santiago de Chile: Fondo de Cultura Económica.

Benvenuti, S. (2016). La via francese alla giustizia costituzionale. Napoli: ESI.

Bergh, A. E. (1907). The Writings of Thomas Jefferson. Washington D. C.

Biagi, F. (2016). Corti costituzionali e transizioni democratiche. Bologna: Mulino.

Bilancia, P. y De Marco, E. (2004). La tutela multilivello dei diritti. Milano: Giuffré.

Blanco Valdés, R. (1994). El valor de la Constitución. Madrid: Alianza.

Blume Fortini, E. (1996). El control de la constitucionalidad. Lima: Ersa. 
Brewer Carías, A. R. (2005). La reforma del sistema de justicia constitucional en Honduras. Revista Iberoamericana de Derecho Procesal Constitucional, 4, 55-77.

- (2006). La aplicación de los tratados internacionales sobre derechos humanos en el orden interno. Revista Iberoamericana de Derecho Procesal Constitucional, 6, 29-78.

- (2014). Orígenes del constitucionalismo moderno en Hispanoamérica. Caracas: Editorial Jurídica Venezolana.

Butturini, D. (2009). La tutela dei diritti fondamentali nell'ordinamento costituzionale italiano ed europeo. Napoli: ESI.

Calabresi, G. (2008). A critical introduction to the originalism debate. Harvard Law Journal of Law and Public Policy, 31, 875-897.

Cammarata, R. (2006). I diritti dei popoli indigeni. Lotte per il riconoscimento e principio di autodeterminazione. Sociologia del diritto, 1, 45-86.

Canotilho Gomes, J. (2001). Constituição Dirigente e vinculação do legislador: contributo para a compreensão das normas constitucionais programáticas. Coimbra: Coimbra Editora.

Cappelletti, M. (1957). La pregiudizialità costituzionale nel processo civile. Milano: Giuffrè.

Caravita, B. (1985). Corte, "giudice a quo" e introduzione del giudizio sulle leggi. La Corte costituzionale austriaca. Padova: Cedam.

Carducci, M. (1998). Il costituzionalismo "parallelo" delle nuove democrazie. Africa e America Latin. Milano: Giuffé.

- (1999). Il costituzionalismo "parallelo" delle nuove democrazie. Milano: Giuffrè.

Carmona Cuenca, E. (1992). Las normas constitucionales de contenido social: delimitación y problemática de su eficacia jurídica. Revista de Estudios Políticos, 76, 103-125.

Carnota, W. (2011). La diferencia entre control de constitucionalidad, control de convencionalidad y control de compatibilidad. Anuario Iberoamericano de Justicia Constitucional, 15, 103-125.

Carozza, P. (1985). La Cour d'arbitrage belga come corte costituzionale. Padova: Cedam.

Carrillo García, Y. y Cruz Carrillo, J. P. (2016). Algunos límites a la justicia indígenas en Ecuador. Ratio Juris, 11, 155-188. Disponible en: https://doi.org/10.24142/ raju. v11n23a6.

Cascajo Castro, J. L. (1978). Kelsen y la Constitución española de 1931. Revista de Estudios Políticos, 1, 243-256.

- (1988). La tutela constitucional de los derechos sociales. Madrid: Civitas.

- (2011). Derechos sociales y principios rectores. En Actas del IX Congreso de la Asociación de Constitucionalistas de España (Santa Cruz de Tenerife, 27 y 28 de enero, 2011).

Castellà Andreu, J. (2016). Tribunal Constitucional y proceso secesionista catalán: respuestas jurídico-constitucionales a un conflicto político-constitucional. Teoría y Realidad Constitucional, 37, 561-592. Disponible en: https://doi. org/10.5944/trc.37.2016.17021. 
Castro Lozano, J. (2002). La justicia constitucional y la interpretación de la Constitución en México. México: UNAM.

Catalano, S. (2016). La question prioritaire de constitutionnalité in Francia. Napoli: ESI

Catelani, E. (1993). La determinazione della "questione di illegittimità costituzionale" nel giudizio incidentale. Milano: Giuffrè.

Ceccherini, E. (2002). La codificazione dei diritti nelle recenti Costituzion. Milano: Giuffré.

Cerrina Feroni, G. (2002). Giurisdizione costituzionale e legislatore nella Repubblica federale tedesca. Torino: Giappichelli.

Corrêa Souza De Oliveira, F. (2015). Eficácia positivas das normas programáticas. Revista Brasileira de Direito, 11, 35-44. Disponible en: https://doi. org/10.18256/2238-0604/revistadedireito. v11n1p34-45.

Costa Pinto, A. (2006). Authoritarian legacies, transitional justice and state crisis in Portugal's democratization'. Democratization, 2, 173-204. Disponible en: https://doi.org/10.1080/13510340500523895.

Crisafulli, V. (1957). Incostituzionalità o abrogazione? Giurisprudenza costituzionale, 271.

- (1978). La Corte vent'anni, in La norma costituzionale tra norma giuridica e realtà sociale. Bologna: Mulino.

Cruz Angulo Nobara, J. (2017). El Juicio de Amparo en la Ley de 2013. En VV. AA. El Poder judicial de la Federación y los grandes temas del constitucionalismo (pp. 105-132). México: Instituto Nacional de Estudios Históricos de la Revolución Mexicana.

Cruz Villalón, P. (1982). Dos modos de regulación del control de constitucionalidad: Checoslovaquia (1920-1938) y España (1931-1936). Revista Española de Derecho Constitucional 2, 115-146.

- (1987). La formacción del sistema europeo del control de constitucionalidad (19181939. Madrid: Centro de Estudios Constitucionales.

D’Andrea, L. (2005). Ragionevolezza e legittimazione del sistema. Milano: Giuffrè.

De Otto Pardo, I. (1977). Qué son la Constitución y el Proceso constituyente. Barcelona: La Gaia Ciencia.

- (2010). La competencia del Tribunal Constitucional en relación con la disposición derogatoria de la Constitución, in Obras completas. Madrid: Centro de Estudios Políticos y Constitucionales.

Delledonne, G. y Martinico, G. (2019). The Canadian Contribution to a Comparative Law of Secession. Palgrave: Macmillan. Disponible en: https://doi. org/10.1007/978-3-030-03469-6.

Díaz, E. (1987). La transición a la democrazia. Madrid: Eudema.

Díaz Revorio, F. J. (2001). El control de constitucionalidad de las omisiones legislativas relativas en el derecho comparado europeo. Revista Española de Derecho Constitucional, 61, 81-130.

Díez-Picazo, L. M. (1985). Consideraciones en torno a la inconstitucionalidad sobrevenida de las normas sobre la producción jurídica y a la admisibilidad de 
la cuestión de inconstitucionalidad. (Comentario a la Sentencia del Tribunal Constitucional de 24 de julio de 1984). Revista Española de Derecho Constitucional, 13, 147-156.

Eguiguren Praeli, F. J. (2003). Aplicación de los tratados internacionales sobre derechos humanos en la jurisprudencia constitucional peruana. Ius et Praxis, 1. Disponible en: dx. doi.org/10.4067/S0718-00122003000100009.

Eissa Barroso, F. (2010). Mirando hacia Filadelfia desde Anahuác: la Constitución estadounidense en el Congreso Constituyente mexicano del 1823-1824. Política y Gobierno, 15, 97-125.

Enríquez Viñas, M. (2017). Derogación tacita o inaplicabilidad de preceptos legales preconstitucionales. Estudios Constitucionales, 1, 307-328. Disponible en: https://doi.org/10.4067/S0718-52002017000100010.

Escobar, M. G. (2005). Democracia e instituciones en América Latina. Madrid: Dykinson.

Espinosa-Saldaña Barrera, E. y Cruces Burga, A. (2015). Apuntes sobre la evolución de los derechos sociales, económicos y culturales en el Perú y los alcances de su judiciabilidad. Themis, 67, 101-116.

Favoreu, L. y Philippe, L. (2005). Le Conseil constitutionnel. Paris: PUF. Disponible en: https://doi.org/10.3917/puf. favor.2005.01.

Fernández Fernández, V. y Samaniego Behar, N. (2011). El juicio de amparo: historia y futuro de la protección constitucional en México. Revista IUS, 5 (27), 173200. Disponible en: https://doi.org/10.35487/rius.v5i27.2011.84.

Fernández Rodríguez, J. (2007). La justicia constitucional europea ante el siglo XXI. Madrid: Tecnos.

Fernández Segado, F. (1997). Los inicios del control de la constitucionalidad en Iberoamerica: del control político al control jurisdiccional. Revista Española de Derecho Constitucional, 49, 79-118.

- (2000). La jurisdicción constitucional en América latina. Montevideo: Ingranusi.

- (2002). La jurisdicción constitucional en Bolivia. México: UNAM.

- (2008). El control de constitucionalidad de las omisiones legislativas. Algunas cuestiones dogmáticas. Revista de las Cortes Generales, 1, 7-80.

Ferrer MacGregor, E. (2008). Derecho procesal constitucional. Madrid: Marcial Pons.

- (2009). Mauro Cappelletti y el derecho procesal constitucional comparado. Anuario Iberoamericana de Justicia Constitucional, 13, 267-306.

- (2002). Los Tribunales constitucionales en Iberoamérica, México: UNAM.

Ferrer MacGregor, E. y Sánchez Gil, R. (2013). El nuevo juicio de amparo. Guía de la reforma constitucional y la nueva Ley de Amparo. México: Porrúa.

Ferrer MacGregor, E. y Silva García, F. (2011). Jurisdicción militar y derechos humanos. El caso Radilla ante la Corte Interamericana de Derechos Humanos. México: Porrúa.

Ferrer Muñoz, M. y Luna Carrasco, J. (1996). Presencia de doctinas constitucionales extranjeras en el primer liberalismo mexicano. México: UNAM. 
Figueroa, R. (2000). De por qué no debemos prestar tanta atención al argumento genético en la interpretación constitucional. Revista de Ciencias Sociales, 45, $137-156$.

Fioravanti, M. (2009). Costituzionalismo: percorsi di storia e tendenze attuali. Bari: La-terza.

Fiz Zamudio, H. (1991). La justicia constitucional en América Latina. Lecturas constitucionales andinas. Lima: Comisión Andina de Juristas.

- (1999). Aproximanción al derecho procesal constitucional. Anuario Iberoamerica de justicia constitucional, 3, 89-119.

- (2006). Protección jurídico constitucional de los derechos humanos de fuente internacional en los ordenamientos de Latinoamérica. Derecho constitucional para el siglo XX. Navarra.

Floridia, G. (1991). La costituzione dei moderni. Torino: Giappichelli.

Gambino, S. (1988). Sistema delle fonti e controllo della costituzionalità. Il caso francese. Torino: Giappichelli.

- (2009). Diritti fondamentali e Unione europea. Milano: Giuffré.

García Balaunde, D. (1989). Teoría y práctica de la Constitución peruana. Lima: Eddili.

- (1999). De la jurisdicción constitucional al Derecho procesal constitucional. Anuario Iberoamericano de Justicia Constitucional, 3, 121-155.

- (2000). El Tribunal de Garantías constitucionales y sociales de Cuba. Anuario Iberoamericano de Justicia Constitucional, 4, 125-143.

- (2003). Existe un espacio público latinoamericano? Estudios Constitucionales, 1, 61-70.

García de Enterría, E. (1981). La posición jurídica del Tribunal Constitucional en el sistema español: posibilidades y perspectivas. Revista Española de Derecho Constitucional, 1, 39-131.

- (1984). La Constitución como norma y el Tribunal Constitucional. Madrid: Civitas.

- (1985). La Constitución como norma y el Tribunal Constitucional. Madrid: Civitas.

García Laguardia, J. (1971). Orígenes de la democracia constitucional en Centro América. San José: Editorial Universitaria Centroamericana.

Gardino, A. (1988). Giudici e Corte costituzionale nel sindacato sulle leggi. Milano: Giuffrè.

Garriga, G. (2010). Historia y Constitución: trayectos del constitucionalismo hispano. México: Instituto Mora.

Goldford, D. J. (2005). The American Constitution and the Debate over Originalism. New York: Cambridge University Press. Disponible en: https://doi. org/10.1017/CBO9780511756214.

Gómez, G. (1996). El control de constitucionalidad y el Tribunal Constitucional de 1980. Cuadernos de Análisis Jurídico, 31, 269-278. Disponible en: http://www. udp. cl/facultades_carreras/derecho/publicaciones. asp 
González Pérez, L. (2013). Aplicación de los tratados internacionales y la jurisprudencia de la CIDH en la protección de la libertad de expressión. Revista de la Facultad de Derecho de México, 259, 199-234. Disponible en: https://doi. org/10.22201/fder.24488933e.2013.259.60579.

Gross Espiell, H. (2002). El constitucionalismo latinoamericano y la codificación en el siglo XIX. Anuario Iberoamericano de Justicia Constitucional, 6, 143-175.

Hernández Gil, A. (1982). El cambio político español. Bacelona: Planeta.

Hernández Valle, R. (1997). La jurisdicción constitucional en Costa Rica. En D. García Balaunde (coord.). La jurisdicción constitucional en Iberoamérica (pp. 499-531). Madrid: Dykinson.

- (2006). El principio de igualdad y las omisiones legislativas. En M. Carrasco Durán, F. J. Pérez Royo, J. Urías Martínez y M. J. Terol Becerra (coords.). Derecho constitucional para el siglo XXI (pp. 635-644). Madrid: Aranzadi.

- (2010). L'utilizzazione della giurisprudenza della Corte americana dei diritti dell'uomo da parte dei Supremi tribunali e dei Tribunali costituzionali dell'America latina. En G. Rolla (ed.). Il sistema europeo di protezione dei diritti fondamentali e i rapporti tra le giurisdizioni. Milano: Giuffrè.

- (1997). Escritos sobre justicia constitucional. San José: DIKE.

Herrera Andrade, E. (2011). Justicia constitucional en Colombia antes y después de la Constitución de 1999. En J. M. López Ulloa (dir.). La justicia constitucional en Iberoamérica (pp. 97-126). Cádiz: Universidad de Cádiz.

Herrera García, A. (2015). El objeto de protección del nuevo juicio de amparo mexicano. Revista Derecho del Estado, 34, 153-181. Disponible en: https://doi. org/10.18601/01229893. n34.08.

Huppmann, R. (2000). La giustizia costituzionale in Austria. En J. Luther, R. Romboli y R. Tarchi (eds.). Esperienze di giustizia costituzionale. Torino: Giappichelli.

Huscroft, G. y Miller, B. W. (2011). The Challenge of Originalism: Theories of Constitutional Interpretation. New York: Cambridge University Press. Disponible en: https://doi.org/10.1017/CBO9781139003926.

Iacobucci, F. (2004). La Carta vent'anni dopo. En S. Gambino (ed.). La protezione dei diritti fondamentali. Europa e Canada a confronto. Milano: Giuffrè.

Iacometti, M. (2009). Il progetto di Costituzione federale della I Repubblica spagnola del 1873. In E. de Marco (ed.). Studi in memoria di Giuseppe G. Floridia (pp. 373-411). Napoli: Jovene.

Jiménez Asensio, R. (2001). El constitucionalismo. Oñati: IVAP.

Jiménez Campo, J. (1997). La sentencia sobre la constitucionalidad de la ley. Madrid: Centro de Estudios Constitucionales.

- (1981). Crisis política y transición al pluralismo en España (1975-1978). En E. García de Enterría y A. Predieri (dirs.). La Constitución española de 1978 (pp. 45-96). Madrid: Civitas.

- (1998). La declaración de incostitucionalidad de la ley. En K. Hesse y P. Häberle (eds.). Estudios sobre jurisdicción constitucional. Madrid: McGraw Hill. 
Laise, L. D. (2017). La interpretación de la Constitución de los Estados Unidos de América según el originalismo intencionalista. Revista de Historia Constitucional, 18, 245-292. Disponible en: https://doi.org/10.17811/hc. v0i18.473.

Lanchester, F (1985). Alle origini di Weimar. Il dibattito costituzionale tedesco tra il 1900 e il 1918. Milano: Giuffrè.

Luciani, M. (1984). Le decisioni processuali e la logica del giudizio costituzionale incidentale. Padova: Cedam.

Luther, J. (1990). Idee e storie di giustizia costituzionale nell'Ottocento. Torino: Giappichelli.

Luther, J., Romboli, R. y Tarchi, T. (2000). Esperienze di giustizia costituzionale. Torino: Giappichelli.

Mannella, F. (2011). Giudici comuni e applicazione della Costituzione. Napoli: Editoriale Scientifica.

Maravall, J. M. (1982). La política de la transición. Madrid: Taurus.

Martínez Lazcano, A. J. (2019). Historia del juicio de amparo contra leyes: el amparo Vega. Revista IUS, 13(43), 123-138. Disponible en: https://doi.org/10.35487/ rius. v13i43.2019.331.

Masala, P. (2014). La tutela dei diritti sociali negli ordinamenti di tipo composto:tra uniformità e differenziazione. Pisa: Pisa University Press.

Matia, J. (2016). Cataluña (materiales.

Maxwell, K. (1995). The Making of Portuguese Democracy. Cambridge: Cambridge University Press. Disponible en: https://doi.org/10.1017/CBO9780511582752.

Menéndez Menéndez, E. (1945). La nueva Constitución cubana y su jurisprudencia (1940-1944). La Habana: Jesús Montero Editor.

Merusi F. (1990). Servizi pubblici instabili. Bologna: Il Mulino.

Mezzetti, L. (2000). Le democrazie incerte. Torino: Giappichelli.

- (2002). Transiciones constitucionales y consolidación de la democracia a albores del siglo XXI. Ius et Praxis, 8. Disponible en: http://dx. doi.org/10.4067/ S0718-00122002000200019.

Modugno, F. (2000). Principi e norme. En F. Modugno (ed.). Esperienze giuridiche del '900. Milano: Giuffrè.

Morales Tobar, M. (2005). El Tribunal Constitucional del Ecuador. En J. C. Trujillo Vászquez, R. Viciano Pastor y S. Andrade Ubidia (coords.). Estudios sobre la Constitución ecuatoriana de 1998 (pp. 237-260). Valencia: Tirant lo Blanc.

Morodo, R. (1984). La transición politica. Madrid: Tecnos.

Morrone, A. (2001). Il custode della ragionevolezza. Milano: Giuffrè.

Moscarini, A. (1996). Ratio legis e valutazioni di ragionevolezza della legge. Torino: Giappichelli.

Nogueira Alcalá, H. (1995). El Tribunal Constitucional chileno. En Comisión Andina de Juristas. Una mirada a los Tribunales Constitucionales. Las experiencias recientes. Lima: Comisión Andina de Juristas.

- (1997). La jurisdicción constitucional en Chile. En D. García Belaunde (coord.). La jurisdicción constitucional en Iberoamérica (pp. 533-571). Madrid: Dykinson. 
- (2003). La jurisdicción constitucional sudamericana y su evolución en las últimas tres décadas: algunos aspectos relevantes. Jus et Praxis, 2. Disponible en: http://dx. doi.org/10.4067/S0718-00122003000200003.

- (2004). Consideraciones sobre las sentencias de los Tribunales constitucionales y sus efectos en América del Sur. Jus et Praxis, 10, 113-158.

Ortino, S. (1966). L'esperienza della Corte di Karlsruhe. Milano: Giuffrè.

Ortiz Quiroga, J. A. (2013). La identidad cultural de los pueblos indígenas en el marco de la protección de los derechos humanos y los procesos de democratización en Colombia. Revista Derecho del Estado, 30, 217-249.

Paladin, L. (1997). Ragionevolezza (principio di).

Palici Di Suni, E. (2013). Una Corte costituzionale per l'Austria. Torino: Giappichelli,.

Parejo Alfonso, L. (1981). La Constitución y las leyes preconstitucionales. El problema de la derogación y la llamada inconstitucionalidad sobrevenida. Revista de Administración Pública, 94, 201-223.

Parodi, G. (1996). La sentenza additiva a dispositivo generico. Torino: Giappichelli.

Pasillas, E. (2001). Multiculturalismo y derechos fundamentales en el nordeste de México: El caso de la tribu yaqui. Estudios fronterizos, 19. Disponible en: https://doi.org/10.21670/ref.1808008.

Passaglia, P. (2011). Le Juge constitutionnel et le Législateur. L'expérience italienne. Saarbruken: Editions Universitaires Européennes.

Pegoraro, L. (2019). Sistemi di giustizia costituzionale. Torino: Giappichelli.

Pérez Tremps, P. (1985). Tribunal Constitucional y Poder Judicial. Madrid: Centro de Estudios Constitucionales.

Pineda Camacho, R. (1997). La Constitución de 1991 y la perspectiva del multiculturalismo en Colombia. Alteridades, 14, 107-129.

Pisarello, G. (2007). Los derechos sociales y sus garantías. Elementos para una reconstrucción. Madrid: Trotta.

Piza Escalante, R. (2004). La justicia constitucional en Costa Rica. San José Investigaciones Jurídicas.

Pizzolo, C. (2005). Los crimenes de lesa humanidad no pueden ser objeto de amnistía. El caso argentino y la jurisprudencia actual de la Corte suprema de justicia.

Politi, F. (1997). Gli effetti nel tempo delle sentenze di accoglimento della Corte costituzionale: contributo ad una teoria dell'invalidità costituzionale delle leggi. Padova: Cedam.

- (2018). Diritti sociali e dignità umana nella Costituzione italiana. Torino: Giappichelli.

Ponce Solé, J. (2013). El derecho y la (ir)reversibilidad de los derecho sociales de los ciudadanos. Madrid: INAP.

Rescigno, G. (1972). Le convenzioni costituzionali. Padova: Cedam.

Ridao i Martín, J. (2014). La juridificación del derecho a decidir en España. Revista de Derecho Político, 91, 91-136. Disponible en: https://doi.org/10.5944/ rdp.91.2014.13220.

Ríos Álvarez, L. (2007). El nuevo Tribunal Constitucional chileno. Anuario Iberoamericano de Justicia Constitucional, 11, 243-268. 
Rivera Santiváñez, J. A. (2009). El nuevo sistema constitucional del Estado boliviano. Cochabamba: Kipus.

Roherssen, C. (1983). Hans Kelsen nella cultura filosofica-giuridica del 900. Firenze: Istituto Enciclopedia Italiana.

Rolla, G. (1986). Indirizzo politico e Tribunale costituzionale in Spagna. Napoli: Jovene.

- (2001). Luci e ombre nell'esperienza delle transizioni pactadas. Brevi considerazioni sui limiti della vigente Costituzione del Cile. Diritto pubblico comparato e europeo, 3, 575-599.

- (2006). I caratteri di una società libera e democratica secondo la giurisprudenza della Corte suprema del Canada. En G. Rolla (ed.). Eguali, ma diversi. Identità ed autonomia secondo la giurisprudenza della Corte Suprema del Canada (pp. 1-10). Milano: Giuffré.

- (2010). L'interpretazione adeguatrice tra Tribunale costituzionale e giudici comuni in Spagna. Estudios Constitucionales, 2, 601-632.

- (2012). Profili costituzionali della dignità umana. In A. D'Atena (ed.). Studi in onore di Pierfrancesco Grossi. Milano: Giuffré.

- (2012). La tutela dei diritti costituzionali. Roma: Carocci.

- (2020). Consideraciones sobre la jurisprudencia constitucional en materia de derechos fundamentales, sesenta y dos años después de la primera sentencia de la Corte constitucional italiana. En Los derechos fundamentales en el siglo XXI, II. México: Tirant lo Blanch.

Ron, X. P. (2011). La jurisdicción indígena frente al control de constitucionalidad en Ecuador. ¿Pluralismo jurídico o judicionalización de lo plural? Quito: Corporación Editora Nacional.

Rozo Acuña, E. (2007). Simón Bolivar. Obra politica y constitucional. Madrid:Tecnos.

Rubio Llorente, F. (1982-1983). Del Tribunal de Garantías al Tribunal Constitucional. Revista de Derecho Politico, 16, 27-38. Disponible en: https://doi. org/10.5944/rdp.16.1982.8198.

Rubio Llorente, F. y Aragón Reyes, M. (1982). La giurisdizione costituzionale nella Costituzione spagnola del 1978. En A. Pedrieri (ed.). La Costituzione spagnola del 1978. Milano: Giuffré.

Ruggeri, A. (1988). Le attività “conseguenziali” nei rapporti fra la Corte costituzionale e il legislatore. Milano: Giuffrè.

Ruiz Lapeña, R. M. (1982). El Tribunal de Garantías Constitucionales en la II República española. Barcelona: Bosch.

Sagüés, N. (1991). La jurisdicción constitucional en Costa Rica. Revista de Estudios Políticos, 74, 471-495.

- (2002). Instrumentos de la justicia Constitucional frente a la inconstitucionalidad por omisión. En J. M. Vega Gómez y E. Corzo Sosa (coords.). Instrumentos de tutela y justicia constitucional (pp. 605-619). México: Instituto de Investigaciones Jurídicas.

Sánchez, E. (1998). Justicia y pueblos indígenas. Santa Fe de Bogotá: Universidad Nacional de Colombia, 
Sánchez Agesta, L. (1984). Historia del constitucionalismo español (1808-1936). Madrid: Centro de Estudios Constitucionales.

Sánchez Gil, R. (2012). Escritos procesales constitucionales. México: Porrúa.

Sandal Ramos Koprivitza, U. (2016). Los tratados internacionales en materia de derechos humano: reflexiones sobre su aplicación en México. En C. León Bastos, V. A. Wong Meraz y E. Corzo Sosa (coords.). Derechos humanos: realidades y desafios (pp. 135-156). México: VLEX.

Scaccia, G. (2000). Gli strumenti della ragionevolezza nel giudizio. Torino: Giappichelli.

Scalia, A. (1997). A Matter of Interpretation. Federal Courts and the Law. Princeton: Princeton University Press.

Schaffer, H. (1998). Austria, la relación entre el Tribunal Constitucional y el Legislador. En E. Aja (ed.). Las tensiones entre el Tribunal Constitucional y el Legislador en la Europa actual. Barcelona: Ariel.

Scocozza, A. (2003). Estado y Constitución en Simón Bolívar. Revista de Estudios Interdisciplinarios en Ciencias Sociales, 5, 297-326.

Sergio Verdugo, R. y Francisco García, J. (2013). El (mal) uso de la técnica originalista de interpretación. A propósito del caso de Luciano Cruz-Coke. Revista de Derechos Fundamentales, 10, 137-156.

Serra Cristóbal, R. (1999). La guerra de las Cortes: la revisión de la jurisprudencia del Tribunal supremo a través del recurso de amparo. Madrid: Tecnos.

Silvero Salgueiro, J. (2007). El rol de la Sala constitucional en la democracia paraguaya. En Tribunales constitucionales y consolidación de la democracia. México: Suprema Corte de Justicia de la Nación.

Soberanes Fernández, J. L. (1992). El primer constitucionalismo iberoamericano. Madrid: Marcial Pons.

Solano, N. (2007). La jurisdicción constitucional en el Salvador. Anuario Iberoamericano de Justicia Constitucional, 11, 395-424.

Strauss, D. (2010). The living constitution., New York: Oxford University Press.

Subsay, D. (2019). Constitución y transición a la democracia en América Latina: ensayos selectos. Santiago de Chile: Olejnik.

Terol Becerra, M. y Jimena Quesada, L. (2014). Tratado sobre protección de derechos sociales. Valencia: Tirant lo Blanch.

Teutli Otero, G. (2013). Jerarquía y controles constitucionales. Revista de la Facultad de Derecho de México, 260, 523-546.

Tron Petit, J. C. (1997). La aplicación de los tratados internacionales por los tribunales mexicanos. En El papel del derecho internacional en América: la soberanía nacional en la era de la integracción regional (pp. 143-158). México: UNAM.

Vagli, G. (2001). L'evoluzione del sistema di giustizia costituzionale in Portogallo. Pisa: ETS.

Varela, S. y Satrústegui, M. (1979). Constitución nueva y leyes viejas. Revista del Departamento de Derecho Político, 4, 59-77. Disponible en: https://doi. org/10.5944/rdp.4.1979.7982. 
Varsori, A. (2010). L'Occidente e la Grecia: dal colpo di Stato militare alla transizione alla democrazia (1967-1976). En M. del Pero (ed.). Democrazie. L'Europa meridionale e la fine delle dittature (pp. 5-94). Firenze: Le Monnier.

Vega, F. y Zúñiga F. (2006). El nuevo recurso de inaplicabilidad por inconstitucionalidad ante el Tribunal Constitucional. Revista de Estudios Constitucionales, 2, 135-174.

Vera Lugo, J. P. (2006). La jurisprudencia como campo de reflexión de la diversidad cultural: apropiación jurídica de nociones culturales. Universitas humanisticas, 62, 205-238.

Villarroya, J. T. (1978). El Tribunal Constitucional en el anteproyectyo de Constitución. En Estudios sobres el proyecto de Constitución. Madrid: Centro de Estudios Constitucionales.

Vipiana, P. M. (1993). Introduzione allo studio del principio di ragionevolezza nel diritto pubblico. Padova: Cedam.

Zanon, N. (1990). L'exception d'incostitutionnalité in Francia: una riforma difficile. Torino: Giappichelli.

Zapata, P. (2011), Justicia constitucional. Teoría y práctica en el Derecho chileno y comparado. Santiago: Jurídica de Chile.

Zúñiga, F. (2005). Reforma constitucional. Santiago de Compostela: Lexis Nexis. 